\title{
Improved augmented Lagrangian coordination for optimizing supply chain configuration with multiple sharing elements in industrial cluster
}

Duxian Nie, Ting Qu, Yang Liu, Congdong Li and G. Q. Huang

The self-archived postprint version of this journal article is available at Linköping University Institutional Repository (DiVA):

http://urn.kb.se/resolve?urn=urn:nbn:se:liu:diva-159014

N.B.: When citing this work, cite the original publication.

Nie, D., Qu, T., Liu, Y., Li, C., Huang, G. Q., (2019), Improved augmented Lagrangian coordination for optimizing supply chain configuration with multiple sharing elements in industrial cluster, Industrial management + data systems, 119(4), 743-773. https://doi.org/10.1108/IMDS-06-2018-0253

Original publication available at:

https://doi.org/10.1108/IMDS-06-2018-0253

Copyright: Emerald

http://www.emeraldinsight.com/ 


\section{EEmerald Industrial Management}

\section{Improved Augmented Lagrangian Coordination for Optimizing Supply Chains Configuration with Multiple Sharing Elements in Industrial Cluster}

\begin{tabular}{|r|l|}
\hline Journal: & Industrial Management \& Data Systems \\
\hline Manuscript ID & IMDS-06-2018-0253.R1 \\
\hline Manuscript Type: & Research Paper \\
\hline Keywords: & $\begin{array}{l}\text { Industrial cluster, Supplier selection, Supply chain configuration, } \\
\text { Improved augmented Lagrangian coordination }\end{array}$ \\
\hline \multicolumn{2}{|l}{} \\
\hline
\end{tabular}

\section{SCHOLARONE \\ Manuscripts}


Improved Augmented Lagrangian Coordination for Optimizing Supply Chains Configuration with Multiple Sharing Elements in Industrial Cluster

\begin{abstract}
Purpose - This paper aims to study various combination forms of the three basic sharing elements (i.e. orders sharing, manufacturers capacity sharing and suppliers capacity sharing) in the cluster supply chain, formulate a distributed model to protect enterprises' decision privacy and seek to develop an effective method for solving the distributed complex model.
\end{abstract}

Design/methodology/approach -A distributed assembly cluster supply chain configuration (ACSCC) model is formulated. An improved augmented Lagrangian coordination (ALC) is proposed and used to solve the ACSCC model. A series of experiments are conducted to validate the improved ALC and the model.

Findings - Two major findings are obtained. First, the market order's quantity change and the sales price of the product have great impact on both the optimal results of the ACSCC and the cooperative strategy, especially, when the market order increases sharply, enterprises have to adopt multiple cooperative strategies to complete the order, meanwhile, the lower sales price of the product helps independent suppliers to get more orders. Second, the efficiency and computational accuracy of the improved ALC method are validated as compared to the centralized ALC and Lingo11.

Research limitations/implications -This paper formulated the single-period ACSCC model under certain assumptions, yet a multi-period ACSCC model is to be developed, a more comprehensive investigation of the relationships among combination forms is to be extended further and a rigid proof of the improved ALC is necessary.

Practical implications -Enterprises in the industrial cluster should adopt different cooperative strategy in terms of the market order's quantity change and the sales price of the product.

Social implications-The proposed various combination forms of sharing elements and formulated the ACSCC model provide guidance for the managers in the industrial cluster to choose the proper policy.

Originality/value -This research studies various combination forms of the three basic sharing elements in the cluster supply chain. A distributed ACSCC model has been established considering simultaneously multiple sharing elements. An improved ALC is presented and applied to the ACSCC problem.

Keywords: Industrial cluster, Supplier selection, Supply chain configuration, Improved augmented Lagrangian coordination

Article Type: Research paper 


\section{Introduction}

With the global economic slowdown, falling commodity prices, the implementation of energy-saving emission reduction standards, early excessive credit growth and the negative effect of geopolitical unrest and other factors, the global market competition intensifies day by day (Luo 2007). To achieve profitability, enterprises must not only improve product quality, reduce production cost and energy consumption, but also face up with the ever-changing market demand. However, since most small and medium enterprises' production technology is backward, facilities are small-scale, varieties of products are few, funds are in shortage and ability to acquire information is limited, it is difficult to rely on their own ability to accomplish these tasks and adapt to dramatic changes in market environment. Industrial cluster, which is adopted by many countries as a new type of economic development model (Porter 2000), provides a natural platform for small and medium enterprises to cooperate with each other (Roelandt et al. 1999). Cluster supply chain (CSC) is a complex network system formed by the coupling of supply chain and industrial cluster, which has the characteristics of regional proximity, industrial correlation, and cooperation ( $\mathrm{Li}$ et al. 2012). CSC can help small and medium-sized enterprises to reduce their production energy consumption, improve enterprises' ability to resist risks and contribute to achieving profitability through resource sharing (such as order sharing), etc. For example, enterprises of the assembly supply chain in an industrial cluster coordinate each other more easily and conveniently than those of the traditional assembly supply chain because they have clustering characteristics (e.g. geographical proximity and mutual cooperation) (Qu et al. 2017).Therefore, the research on the operation of an industrial cluster, especially the CSC operation, is of great significance to the development of regional economy.

Supply chain configuration (SCC) proposed by Graves and Willems (2001) is a complex overall decision-making process oriented to the whole supply chain operation. The aim of SCC is to optimize certain performance indicators (such as time, cost and quality) of the supply chain by configuring each supply chain node (Huang and Qu 2008). According to the definition of SCC, Cluster supply chain configuration (CSCC) was proposed in the literature (Qu et al. 2015). Customer demand diversity and high-frequency change make the production of cluster system based on orders sharing possess the characteristics of natural dynamic and short life cycle, which is an important characteristic of CSC. Thus, oriented to the order, it is a crucial stage of the CSC operation to promptly and effectively configure and reconfigure a CSC. 
The CSCC decision process is highly complicated because of the dynamic cooperation among single supply chains and the characteristic of the short life cycle of CSC. Therefore, in an industrial cluster, for uncertain customer demands, the alliance leader taking charge of allotting orders and coordinating multiple single supply chains, which configures the system of CSC considering simultaneously multiple sharing elements (e.g. orders sharing, manufacturers capacity sharing, suppliers capacity sharing), is faced with the following challenges. First, both single supply chains and suppliers pertaining to the system of CSC could collaborate for the same supply order (Camarinha-Matos et al. 2009; Kawtummachai et al. 2005), enabling multiple suppliers and single supply chains to be configured in a complicated networked way. Second, there are a series of sharing relationships among cluster enterprises, but they are not willing to share the decision autonomy of theirs to obtain the order from the alliance leader. Third, Qu et al (2015) considered the single-period CSCC problem with a single component order subcontracting among single supply chains and multiple sourcing from independent suppliers, and that $\mathrm{Qu}$ et al (2017) studied the single-period assembly cluster supply chain configuration (ACSCC) problem of the brand product composed of core components and non-core components, but few researchers focused on the study of the CSCC problem considering simultaneously multiple sharing elements(e.g. orders sharing, manufacturers capacity sharing, suppliers capacity sharing). Lastly, previous studies have focused more on All-in-One (AIO) optimization methods (such as dynamic programming, genetic algorithm etc.). Few people adopt multidisciplinary design optimization (MDO) method, especially, employ the improved augmented Lagrangian coordination to configure the ACSCC of system, except that analytical target cascading (ATC) was used to solve the optimal configuration of decentralized supply chains with unlimited capacity because it is very difficult for us to use AIO methods to solve the problem of SCC (Huang and Qu 2008).However, ATC is not capable of being used to configure the CSC with complex network structures.

Augmented Lagrangian coordination (ALC) proposed by Tosserams et al. (2008) is a decomposition-based MDO method, which supports both quasi-separable coupling among elements and function couplings (e.g. objective function coupling and constraint function coupling). It is proved that ALC can effectively solve the CSCC problem with complex and dynamic collaboration relationships among cluster enterprises (Qu et al. 2015, 2017).

In this paper, we investigate the use of ALC in dealing with the optimal configuration of 
assembly supply chains considering simultaneously multiple sharing elements in an industrial cluster. The major research questions of this paper are as follows. First, typical clustering structures and operations of assembly cluster supply chain (ACSC) were investigated. Second, the improved ALC proposed in this paper was extended for the ACSCC problem considering simultaneously multiple sharing elements. Third, the optimization of the effectiveness and efficiency between ALC and the improved ALC was compared to provide a useful reference for researchers.

The remainder of this paper is organized as follows. Section 2 reviewed the literature about the SCC, CSCC, ALC, and stated briefly the gaps of current research. Section 3 investigated the formation mechanism of each combination form, which consisted of three type of sharing elements in the cluster supply chain, and analysed the current solution challenges. The principle of ALC method was introduced and an improved ALC method was presented in section 4, which was then applied to the ACSCC modelling in Section 5, and results were analysed with sensitivity analysis. Finally, in Section 6 conclusions were drawn and future research directions were outlined.

\section{Literature review}

\subsection{Supply chain configuration}

Since the SCC problem was put forward by Graves and Willems (2001), many researchers have made a lot of research on this problem, including the SCC model (e.g. Huang et al. 2005; Meysam et al. 2016; Amini, M. \& Li, H 2015; Klosterhalfen et al. 2014), supplier selection (e.g. Rezaei et al. 2016; Kannan et al.2013), and various AIO optimization methods for SCC solution, such as dynamic programming(DP) (Klosterhalfen et al. 2014), genetic algorithm(GA) (Afrouzy et al. 2016; Huang et al. 2005), etc. However, with the increasing competition in the market, enterprises should make their own decisions to protect privacy in order to obtain profits. Such a SCC problem cannot be solved using the traditional AIO methods (e.g. DP, GA). A few researchers applied ATC to resolve the decentralized SCC problem. Huang and Qu (2008) extended ATC for SCC with alternative autonomous suppliers. And extended ATC was also applied for configuring assembly supply chains with convergent structures (Qu et al. 2010). However, ATC is not able to deal with non-hierarchical partitions (e.g. network structures).

2.2 Cluster supply chain configuration

At present, there is little research on cluster supply chain configuration (CSCC) except for the literature (Qu et al 2015, 2017). Most related research on CSCC mainly is focused on the following 
aspects, first, the relationships between supply chains and industrial cluster (DeWitt et al.2006); second, horizontal across-chain cooperation among single supply chains (Li et al. 2012; Bikram et al. 2009); third, order allocation (Renna et al. 2015; Xiang et al. 2014). For solving methods, because most of them were AIO models assuming the supreme decision right, AIO methods (e.g. GA) were applied to solve them (Li et al. 2012; Xiang et al. 2014; Renna et al. 2015; Afrouzy et al.2016).

\subsection{Augmented Lagrangian coordination}

ALC proposed by Tosserams et al. (2008) is another MDO method based on decomposition and coordination. The application of ALC includes two processes, first, partitioning a system into subsystems that have independent decision rights and can be designed, second, coordinating each of subsystems towards a global optimal solution of the system. Subsystems are coupled by either linking variables or coupling functions. At present, the research on ALC is mainly focused on the following aspects: the update strategy of the penalty weights (Xu et al., 2015), consistency constraint allocation (Allison et al., 2010) and solution of complex engineering problems (Tosserams et al. 2010a, 2010b). Yet, with the intensification of competition and the need for protection of private decisions among enterprises in an industrial cluster, ALC was also successfully used in supply chain management to solve the optimization of CSCC problems (Qu et.al 2015, 2017).

The above literature reviewed shows that there is little research on CSCC, especially ACSCC. Our study differs from the existing literature in that typical clustering structures and operations of assembly cluster supply chain are investigated considering multiple sharing policies (e.g. orders sharing, manufacturer capacity sharing, supplier capacity sharing), particularly, allowing cross-chain to source from private suppliers of other single supply chains. A distributed ACSCC model with multiple kinds of complex couplings among participants of the CSC system is set up, in order to use more efficient ALC to resolve the ACSCC model considering simultaneously multiple sharing elements, an improved ALC is proposed.

\section{Problem description}

3.1 Assembly cluster supply chain configuration process

This research considers the operational mode and configuration of an assembly CSC that consists of multiple assembly single supply chains and lots of independent suppliers $(\mathrm{O})$ dispersed in an industrial cluster. Each single supply chain, which produces the same product assembled by multiple different components, is composed of an assembly manufacturer (M) and its long-term cooperative 
private suppliers (S). Facing the uncertainty of market demand and the diversification of customer's demand, the assembly manufacturer adopts different strategies (e.g. horizontal order-subcontracting and components sourcing) according to the customer's different orders. The horizontal order-subcontracting is that the manufacturer remains enough orders to itself based on the capacity and then horizontally subcontracts the rest of the order to other single supply chains. The components sourcing strategy is that the manufacturer sources components from his private suppliers first, and then sources from independent suppliers or cross-chain sources from other private suppliers of sing supply chains considering cost, quality and time, etc.

3.2 Elementary sharing modes in a cluster

According to the different sharing policies (i.e. order subcontract, private capacity sharing and independent suppliers capacity sharing or multiple sourcing from independent suppliers outside the single supply chain), we can categorize cooperation between participants in an industrial cluster into three basic forms, as shown in Fig.1 (a), (b), (c), respectively. The different sharing policies are indicated by the rough dotted arrow in the Fig.1. Node L represents the alliance leader, who is the manufacturer of some single supply chain and owns the original order.
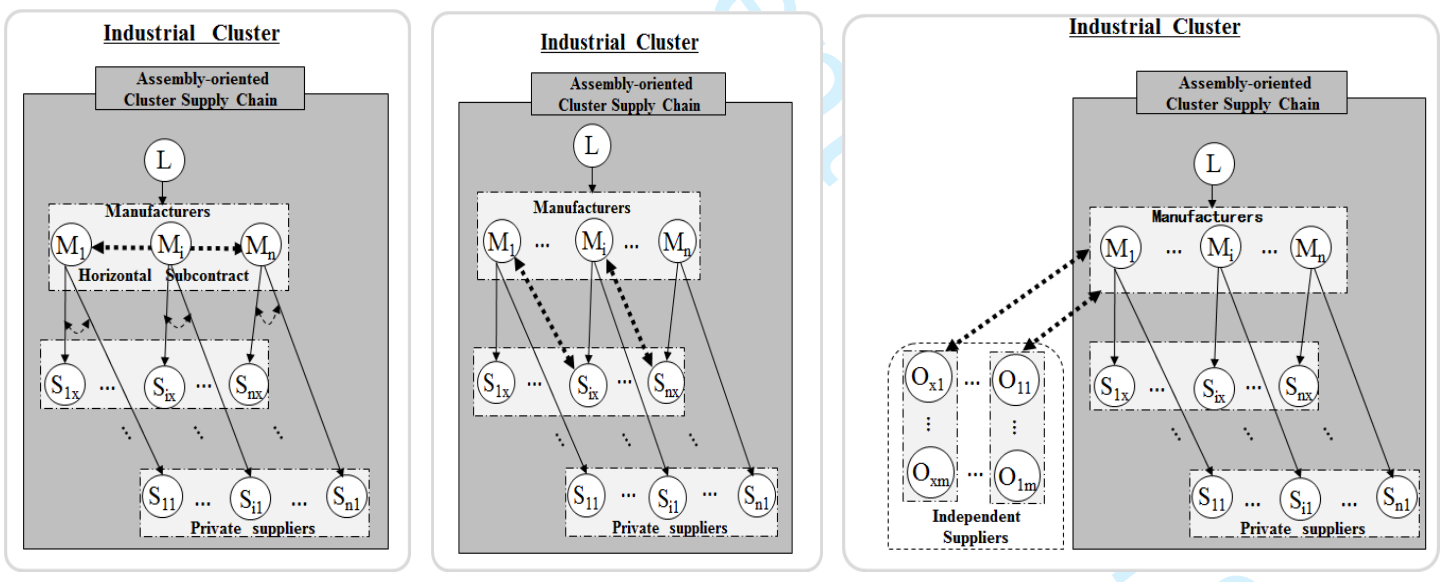

(a) Manufacturer capacity sharing (b) Private suppliers capacity sharing (c) Independent suppliers capacity sharing

Fig.1. Sharing relationships among participants of the CSC system

The first basic form shown in Fig.1 (a) represents the manufacturer capacity sharing, that is, the manufacturer remains enough orders to itself based on the capacity and then horizontally subcontracts the rest of the order to other single supply chains. The second basic form shown in Fig.1 (b) is that the excess capacity of manufacturer's private suppliers can be shared with other single supply chains. The last basic form shown in in Fig.1 (c) represents that independent suppliers are open to all manufacturers 


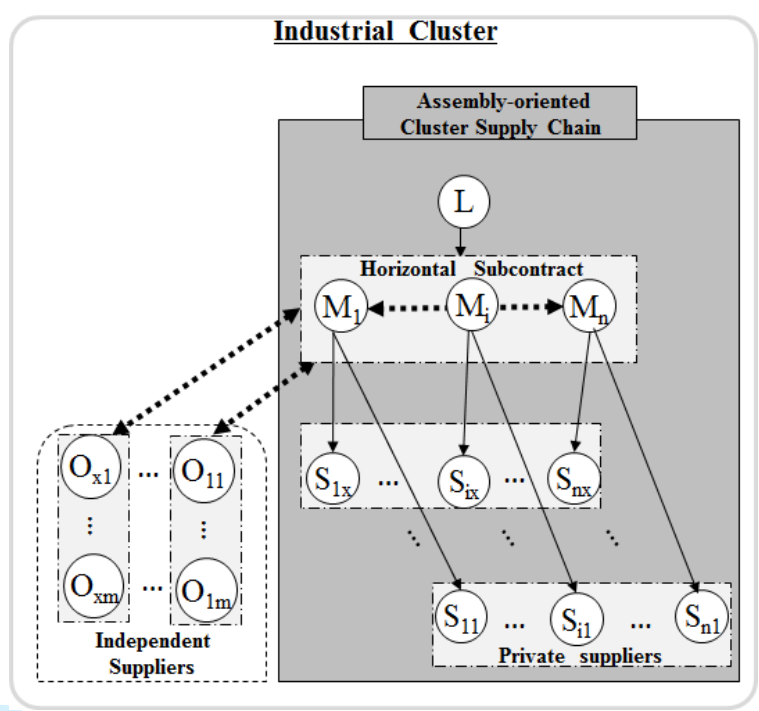

(b) Operation mode 2 of CSC

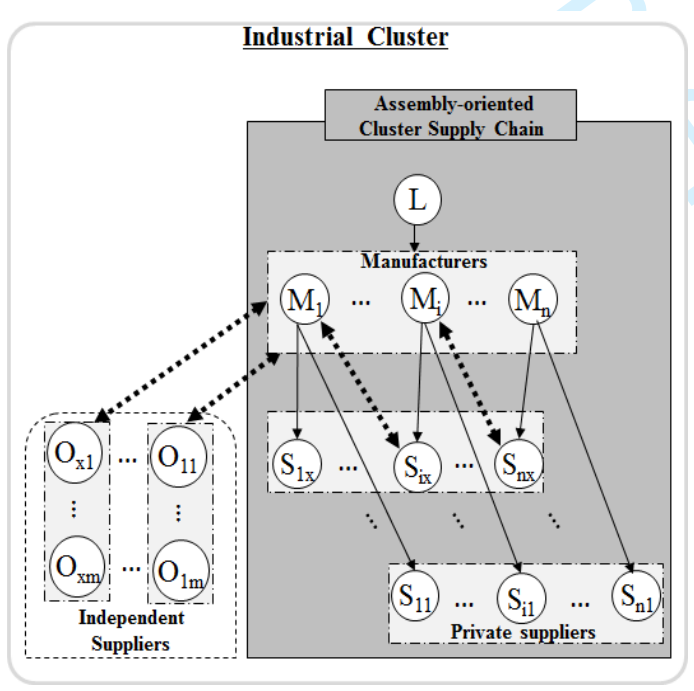

(c) Operation mode 3 of CSC

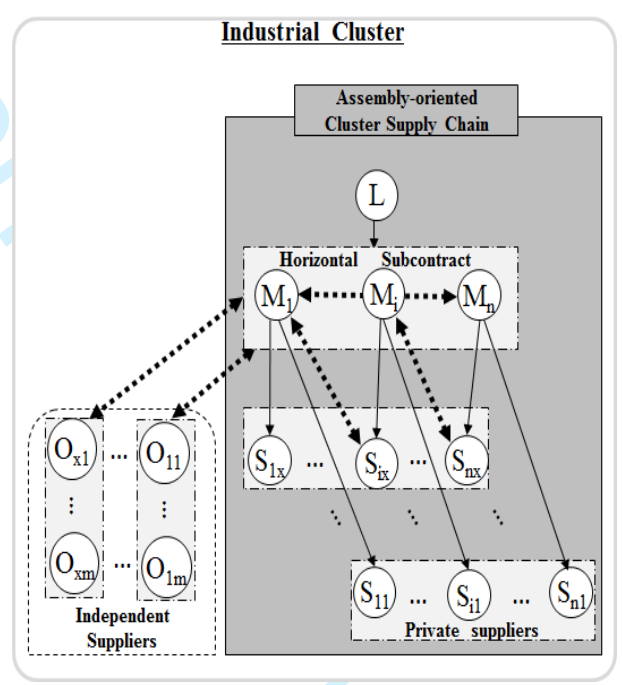

(d) Operation mode 4 of CSC

Fig.2 The combination form of the sharing relationships among participants of the CSC system

Based on cooperative relationships among the participants in the cluster system, the above three basic forms are combined to obtain the following four different cluster system structure modes, as shown in Fig.2. In order to meet the market demand fluctuation, cluster enterprises make full use of the advantages of cluster resource sharing, and each of system structure modes has a different operation mechanism. 
Fig.2 (a) shows that the production enterprise (manufacturer) remains enough orders to itself based on the capacity and then horizontally subcontracts the rest of the order to other single supply chains in terms of cost, quality and time, etc. The purchasing strategy is that the production enterprise (manufacturer) obtained orders sources from its private suppliers first if its own private suppliers have run out of their limited production capacity, it may cross-chain source from private suppliers of other single supply chains.

Fig.2 (b) indicates that there are many independent suppliers of each component, and the subcontracting strategy of production enterprise (manufacturer) obtained orders is the same as that showed in Fig.2 (a). The purchasing strategy is that the production enterprise obtained orders also sources from its private suppliers first, if its own private suppliers have used up their limited production capacity, then it may source from independent suppliers outside the single supply chain. However, cross-chain procurement from other private suppliers is not allowed.

Fig.2 (c) illustrates that each component has lots of independent suppliers, and that the order quantity that production enterprise obtained does not exceed the capacity of the production enterprise. The purchasing strategy is that the production enterprise sources from its private suppliers first, too, if its private suppliers have exhausted their limited production capacity, and it cross-chain sources from private suppliers of other single supply chains or sources from independent suppliers outside the single supply chain.

As shown in Fig.2 (d), there exist many independent suppliers of each component in an industrial cluster. With the increase in the demand for the cluster market orders, the production enterprise remains enough orders to itself based on the capacity and then horizontally subcontracts the rest of the order to other single supply chains considering cost, quality, and arrival time, etc. Its purchasing strategy is the same as that shown in Fig.2 (c).

The common operational strategy from the above four modes can be summarized as the market-oriented manufacturing enterprises of single supply chains receive separately orders. The manufacture obtained the order when its decision needs, according to certain rules, horizontally subcontracts the part of the order to other manufacturing enterprises. A manufacturer sources from its private suppliers first, and then sources from independent suppliers or cross-chain purchases from other private suppliers with multiple sourcing strategies in terms of cost optimization, price control, and arrival time, etc. when the received order is large or urgent or special parts demand urgent. This 
research is primarily concerned with the mode structure shown in Fig.2 (d), because it contains three kinds of sharing elements that the first three modes do not have, this paper focuses on the research of this mode.

3.4 Assembly cluster supply chain configuration modelling

The concept operation mode should be converted into a configurable model based on the corresponding policies before a concrete optimal configuration method is applied. In this paper, apart from the following assumptions, other assumptions and the CSCC policies (i.e. alliance policy, subcontracting policy and sourcing policy) are similar as those in the literature (Qu et al. 2015).

(1) Permit the manufacturer to cross-chain source components from other manufacturers' private suppliers when the capacity of manufacturer's private suppliers is insufficient.

(2) Ignore the impact of the cost of transportation distance on the optimal configuration results of ACSC because of the geographical proximity of enterprises in the industrial cluster.

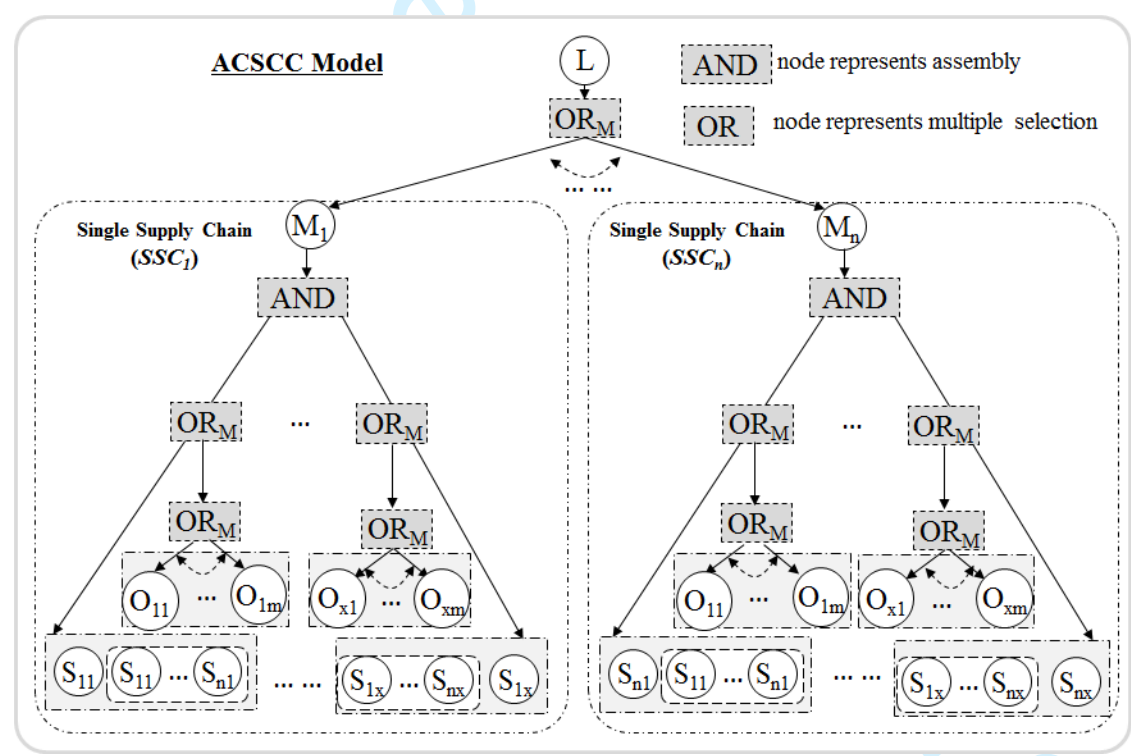

Fig.3 Configuration model of CSC

According to configuration policies, the operational concept mode shown in Fig. 2(d) is converted into an ACSCC model shown in Fig.3.

3.5 Challenges analysis for the optimal ACSCC

As shown in Fig.3, the alliance leader L with the highest decision-making right selects less than 4 cooperative manufacturers of single supply chains in the level below through $\mathrm{OR}_{\mathrm{M}}$ node, while a fixed option is its own manufacturer. According to the corresponding component, each manufacturer selects 
suppliers through $\mathrm{OR}_{\mathrm{M}}$ node, with its private supplier as a fixed option. Therefore, there exist the following challenges when solving the ACSC configuration model shown in Fig.3.

(1) Varied decentralized decision right. There exist multiple kinds of decision rights, i.e. Alliance leader's decision right, manufacturer's decision right and supplier's (private supplier and independent supplier) decision right. Relationships among decision makers form complex networked structures in the configuration processes.

(2) Uncertain structures. During the process of configuring, multiple selection nodes $\mathrm{OR}_{\mathrm{M}}$ let cooperative manufacturers' or suppliers' number uncertain, which makes configuration structures obvious dynamic.

(3) Multi-dimensional couplings. Owing to cooperative relationships between participants in the industrial cluster, there exist multi-dimensional complex couplings among participants. For example, the alliance leader is not only coupled by sharing the same order with selected manufacturers, but also coupled by purchasing components' quantity among suppliers.

(4) Complex and uncertain configuration structures make AIO methods difficultly solve the ACSCC problem.

Facing the above challenges, in this paper, the improved ALC is employed to resolve the ACSCC problem.

\section{Improved augmented Lagrangian coordination}

\subsection{The principle of ALC method}

ALC proposed by Tosserams et al. (2008) is another MDO method based on decomposition and coordination. It has flexible features such as supporting open (hierarchical or non-hierarchical) structures and subsystems coupled through either linking variables or coupling functions, so on. According to whether there exists a master problem, ALC can be dived into two categories: centralized ALC and distributed ALC. The former has an artificial problem as a master problem $\mathrm{P}_{0}$ that coordinates all other sub-problems, while the latter has not.

ALC presented is to solve the MDO problem with M subsystems (Tosserams et al. 2008), which is given by.

$$
\begin{array}{cl}
\min _{z=\left[y^{T}, x_{1}^{T}, \ldots, x_{M}^{T}\right]^{T}} & f_{0}\left(y, x_{1}, \ldots, x_{M}\right)+\sum_{j=1}^{M} f_{j}\left(y, x_{j}\right) \\
\text { s.t. } \quad & g_{0}\left(y, x_{1}, \ldots, x_{M}\right) \leq 0 \\
& h_{0}\left(y, x_{1}, \ldots, x_{M}\right)=0
\end{array}
$$




$$
\begin{aligned}
& g_{j}\left(y, x_{j}\right) \leq 0, j=1, \ldots, M \\
& h_{j}\left(y, x_{j}\right)=0, j=1, \ldots, M
\end{aligned}
$$

4.2 Improved augmented Lagrangian coordination solution approach

A master problem introduced in the centralized ALC is able to make all sub-problems be solved in parallel, but certain new links need to be recreated between each sub-problem and the master problem, which reduces ALC execution efficiency and consumes more computational resources (Xu 2015). The distributed ALC directly uses the problem partition, however, its sub-problems are fully coupled thus need to be solved sequentially. Due to the scale of the ACSCC problem grows much larger and multiple kinds of couplings among decision subsystems of the CSC system, an efficient method and its sub-problems solved in parallel is in need. In this paper, an improved centralized ALC is presented. The improved ALC differs from the centralized ALC in the selection of the master problem. In the improved ALC, we make use of an existing sub-problem as the master problem, which coordinates other sub-problems. The principle of the selection of the existing sub-problem is that the sub-problem is selected if there are the most links between it and other sub-problems. For simplicity without losing generality, we select the existing sub-problem $\mathrm{P}_{\mathrm{k}}$ as the master problem, whose formulation is given by

$$
\begin{gathered}
\min _{\overline{x_{k}=\left[y^{T}, x_{k}^{T}, y_{k}^{T}, x_{0}^{T}\right]^{T}}} f_{0}\left(y, x_{1}, \ldots, x_{M}\right)+f_{k}\left(y_{k}, x_{k}\right)+\sum_{\substack{j=1 \\
j \neq k}}^{M} \phi_{c, j}\left(c_{j}\left(y, y_{j}\right)\right)+\phi_{g}\left(g_{0}, x_{0}\right)+\phi_{h}\left(h_{0}\right) \\
\text { s.t. } \quad g_{k}\left(y_{k}, x_{k}\right) \leq 0, \mathrm{k}=1, \ldots, M \\
h_{k}\left(y_{k}, x_{k}\right)=0, \mathrm{k}=1, \ldots, M
\end{gathered}
$$

The formulation of other sub-problem $p_{j}(j \neq k)$ is given by

$$
\begin{gathered}
\min _{\bar{x}_{j}=\left[y_{j}^{T}, x_{j}^{T}\right]^{T}} f_{0}\left(y, x_{1}, \ldots, x_{M}\right)+f_{j}\left(y_{j}, x_{j}\right)+\phi_{c, j}\left(c_{j}\left(y, y_{j}\right)\right)+\phi_{g}\left(g_{0}, x_{0}\right)+\phi_{h}\left(h_{0}\right) \\
\text { s.t. } \quad g_{j}\left(y_{j}, x_{j}\right) \leq 0, j=1, \ldots, M \\
h_{j}\left(y_{j}, x_{j}\right)=0, j=1, \ldots, M
\end{gathered}
$$

Where the symbolic meaning of formulas (2) and (3) is the same as that of the centralized ALC (Tosserams et al. 2008).

The solution strategy of the improved ALC is similar as that of the centralized ALC. It consists of inner and outer loops, in the outer loops penalty parameters are updated, and in the 
inner loops, the coupled decomposed problem is solved for fixed penalty parameters. Here, the update strategy of penalty parameters is the same as that in the centralized ALC. The concrete solution algorithm is as shown in Fig.4.

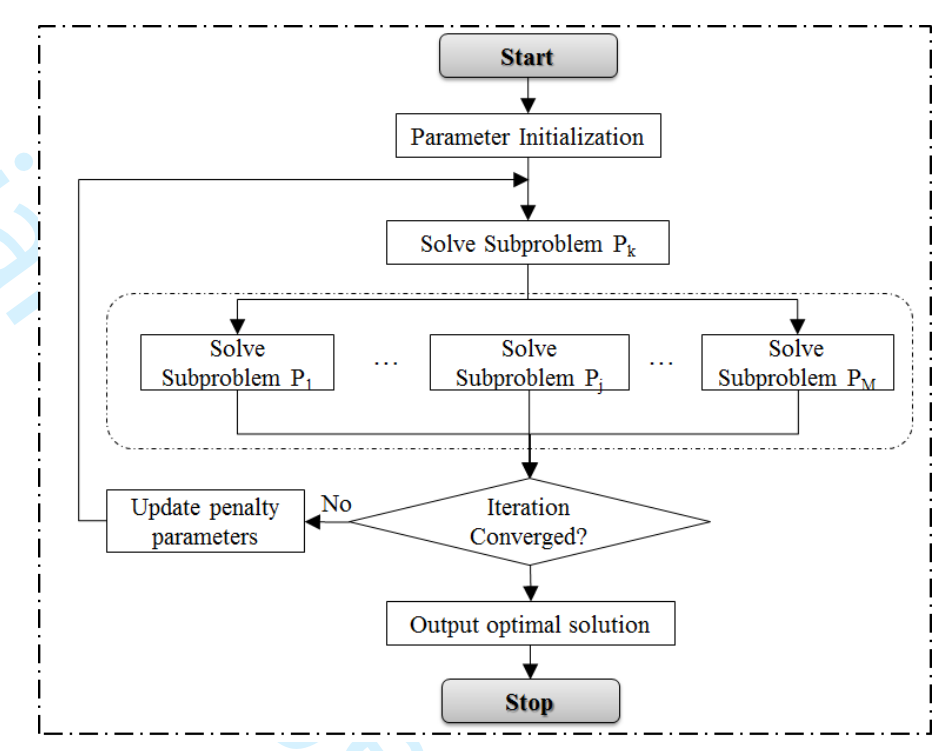

Fig. 4 The coordination solution algorithm of the improved ALC

\section{The improved ALC modelling for cluster supply chain}

\subsection{Model description}

In this paper, based on the above assumptions, a single-period ACSCC problem is studied. Without losing generality, we assume that the manufacturer $\mathrm{M}_{1}$ obtaining the customer order becomes the alliance leader $\mathrm{L}$ that has the highest-level decision right and takes charge of order subcontracting among single supply chains, each single supply chain consists of a manufacturer $\mathrm{M}_{\mathrm{i}}$ and its private suppliers. Because of the pursuit of profit and privacy protection, each of participants (manufactures and suppliers) in the industrial cluster has the independent decision right represented by the solid line circle shown in Fig.5. Single supply chains each produce the same product, which is assembled from two different components, independent suppliers and private suppliers of the component 1 are $O_{11}$ to $O_{1 t}$ and $S_{11}$ to $S_{1 n}$, respectively; independent suppliers and private suppliers of the component 2 are $O_{21}$ to $O_{2 t}$ and $S_{21}$ to $S_{2 n}$, respectively, as shown in Fig.5. 
Considering leader's order subcontracting and the manufacturer's component sourcing, and selecting not more than three suitable single supply chains from all single supply chains( i.e. $\mathrm{SSC}_{1}$ to $\mathrm{SSC}_{\mathrm{n}}$ )and independent suppliers $\left(\mathrm{O}_{11}\right.$ to $\mathrm{O}_{1 \mathrm{t}} ; \mathrm{O}_{21}$ to $\left.\mathrm{O}_{2 \mathrm{t}}\right)$ or cross-chain private suppliers to configure an ACSC, the

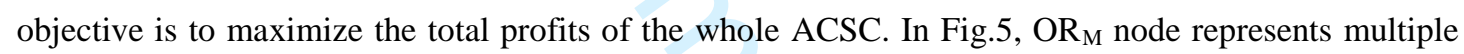
selection (e.g. subcontracting and sourcing), AND node represents assembly. Notations and decision variables used in this paper are given in Table 1.

Table 1 Notation for model parameters and variables.

\begin{tabular}{ll}
\hline \multicolumn{1}{c}{ Notation } & \multicolumn{1}{c}{ Description } \\
\hline Model parameters & Alliance leader \\
$\boldsymbol{L}, \boldsymbol{r}$ & Order of single supply chains \\
$\mathrm{S}_{i j}$ & Total order quantity taken by the alliance leader \\
$Q_{i j}^{s}$ & The private supplier of the $\mathrm{j}^{\text {th }}$ component of the $\mathrm{i}^{\text {th }}$ single supply chain \\
$j$ & Capacity of the $\mathrm{j}^{\text {th }}$ private supplier of the $i^{\text {th }}$ single supply chain \\
$p_{i}$ & Order of private suppliers or components \\
$p_{i j}^{s}$ & Unit sales price of the $i^{\text {th }}$ single supply chain \\
$\theta_{i j}^{s}$ & Unit sales price of the $\mathrm{j}^{\text {th }}$ private supplier of the $i^{i t h}$ single supply chain \\
$c_{j t}^{o}$ & The ratio of the sourcing quantity of the $\mathrm{j}^{\text {th }}$ private supplier of the $i^{\text {th }}$ single \\
$\mathrm{O}_{j t}$ & Unit cost the $t^{\text {th }}$ independent supplier of the $\mathrm{j}^{\text {th }}$ component \\
$t$ & The $t^{\text {th }}$ independent supplier of the $\mathrm{j}^{\text {th }}$ component \\
$M_{i}$ & Order of independent suppliers \\
\hline
\end{tabular}


Total number of the single supply chains in the cluster

Total number of the independent suppliers in the cluster

Unit product sales price of the product alliance leader

$Q_{j t}^{o}$

Capacity of the $t^{\text {th }}$ independent supplier of the $\mathrm{j}^{\text {th }}$ component

$p_{j t}^{o}$

Unit sales price of the $t^{\text {th }}$ independent supplier of the $\mathrm{j}^{\text {th }}$ component

$c_{i j}^{s}$

Unit cost of the $\mathrm{j}^{\text {th }}$ private supplier of the $i^{\text {th }}$ single supply chain

$P Q_{i}$

Capacity of the manufacturer of the $i^{\text {th }}$ single supply chain

$c_{i}$

Unit cost of the assembly manufacturer of the $i^{\text {th }}$ single supply chain

$\lfloor x\rfloor$

The largest integer that is not larger than $x$

\section{ALC solution parameters}

$\begin{array}{ll}\beta, \gamma & \text { The penalty update parameters } \\ \varepsilon & \text { Loop termination tolerance } \\ \alpha & \text { Weight selection parameter }\end{array}$

Decision variables

$d_{i} \quad$ Order proportion subcontracted to the $\mathrm{i}^{\text {th }}$ single supply chain

$\eta_{i} \quad$ Whether the single supply chain $i$ is subcontracted by alliance leader

The $i^{\text {th }}$ single supply chain cross-chain sources the quantity of the component $j$ Zirj from the $\mathrm{r}^{\text {th }}$ private supplier

$d_{i j} \quad$ Sourcing proportion of the component from private supplier $j$ by assembly manufacturer of the $i^{\text {th }}$ single supply chain

$w_{i j} \quad$ Whether the quantity that $\mathrm{i}^{\text {th }}$ single supplier chain manufacturer sources from the $j^{\text {th }}$ private supplier is over capacity of private supplier or not

$y$. The $i^{\text {th }}$ single supply chain sources the quantity of the component $j$ from the $t^{\text {th }}$ independent supplier

\subsection{AIO model of ACSCC system}

As the order subcontracting and component sourcing follows quantity discount prices, we adopt different discount price functions, which are $p_{i}=\left\lfloor\mathrm{p}_{i}\left(1-0.5 * d_{\mathrm{i}}\right)\right\rfloor$ and $p_{r j}^{s}=\left\{\begin{array}{l}p_{i j}^{s}, r=i \\ p_{i j}^{s}\left(1+\mathrm{e}^{-k \theta_{i j}^{s}}\right), r \neq i\end{array}\right.$ where $k$ is a price coefficient (often $\mathrm{k}$ is set to 1$)$. The former represents the sales price step function of the $i^{\text {th }}$ single supply chain, which is discounted according to the order proportion subcontracted $d_{i}$. The latter is the sales price function of the private supplier $\mathrm{j}$ of the $i^{\text {th }}$ single supply chain, and it indicates that the prices remain unchanged if the private supplier $\mathrm{j}$ serves its own single supply chain, otherwise, the prices rise. The sales price function of the component 
$j$ of the $t^{\text {th }}$ independent supplier is the same as that of the $i^{\text {th }}$ single supply chain, that is, $p_{j t}^{o}=\left\lfloor p_{j t}^{o}\left(1-0.5 \theta_{j t}\right)\right\rfloor$, where $\theta_{j t}$ is the ratio of the sourcing quantity of component $j$ from the $\mathrm{t}^{\text {th }}$ independent supplier to its production capacity $Q_{j t}^{o}$. According to the ALC solution procedure given in the literature ( $\mathrm{Qu}$ et al. 2015) as well as the related assumptions, we first establish the following maximum profit of the AIO model of ACSCC.

$$
\max \operatorname{Prf}=P f_{M_{L}}+\operatorname{SumPf}_{M_{i}}+\operatorname{SumPf}_{S}+\operatorname{SumPf}_{S O}
$$

where:

$$
\begin{aligned}
& P f_{M_{L}}=p D-D d_{L} c_{L}-\sum_{i \neq L}^{n} \eta_{i} D d_{i}\left\lfloor p_{i}\left(1-0.5 d_{i}\right)\right\rfloor-\sum_{j=1}^{2}\left[D d_{L} d_{L j}\left(1-w_{L j}\right)+w_{L j} Q_{L j}^{s}\right] p_{L j}^{s}- \\
& \sum_{j=1}^{2} w_{L j} \sum_{r \neq L}^{n} z_{L r j} p_{r j}^{s}-\sum_{j=1}^{2} w_{L j} \sum_{t=1}^{m} y_{L j t}\left\lfloor p_{j t}^{o}\left(1-\frac{y_{L j t}}{2 Q_{j t}^{o}}\right)\right\rfloor \\
& \operatorname{SumPf} f_{M_{i}}=\sum_{i \neq L}^{n} \eta_{i}\left(D d_{i}\left\lfloor p_{i}\left(1-0.5 d_{i}\right)\right\rfloor-D d_{i} c_{i}\right)-\sum_{i \neq L}^{n} \sum_{j=1}^{2}\left[D d_{i} d_{i j}\left(1-w_{i j}\right)+w_{i j} Q_{i j}^{s}\right] p_{i j}^{s}- \\
& \sum_{i \neq L}^{n} \eta_{i} \sum_{j=1}^{2} w_{i j}\left(\sum_{r \neq i}^{n} z_{i r j} p_{r j}^{s}+\sum_{t=1}^{m} y_{i j t}\left\lfloor p_{j t}^{o}\left(1-\frac{y_{i j t}}{2 Q_{j t}^{o}}\right)\right\rfloor\right)
\end{aligned}
$$$$
\operatorname{SumPf}_{S}=\sum_{i=1}^{n} \eta_{i} \sum_{j=1}^{2}\left[D d_{i} d_{i j}\left(1-w_{i j}\right)+w_{i j} Q_{i j}^{s}\right]\left(p_{i j}^{s}-c_{i j}^{s}\right)+
$$$$
\sum_{i=1}^{n} \eta_{i} \sum_{j=1}^{2} w_{i j} \sum_{r \neq i}^{n} z_{i r j}\left(p_{r j}^{s}-c_{i j}^{s}\right)
$$$$
\left.\operatorname{SumPf}_{S O}=w_{L 1} \sum_{t=1}^{m} y_{L 1 t}\left(\left\lfloor p_{1 t}^{o}\left(1-\frac{y_{L 1 t}}{2 \mathrm{Q}_{1 t}^{o}}\right)\right\rfloor-c_{1 t}^{o}\right)+\sum_{i \neq L}^{n} \eta_{i} w_{i 1} \sum_{t=1}^{m} y_{i 1 t}\left(p_{1 t}^{o}\left(1-\frac{y_{L 1 t}}{2 \mathrm{Q}_{1 t}^{o}}\right)\right\rfloor-c_{1 t}^{o}\right)+
$$$$
w_{L 2} \sum_{t=1}^{m} y_{L 2 t}\left(\left\lfloor p_{2 t}^{o}\left(1-\frac{y_{L 2 t}}{2 \mathrm{Q}_{2 t}^{o}}\right)\right\rfloor-c_{2 t}^{o}\right)+\sum_{i \neq L}^{n} \eta_{i} w_{i 2} \sum_{t=1}^{m} y_{i 2 t}\left(\left\lfloor p_{2 t}^{o}\left(1-\frac{y_{L 2 t}}{2 \mathrm{Q}_{2 t}^{o}}\right)\right\rfloor-c_{2 t}^{o}\right)
$$$$
p_{r j}^{s}=\left\{\begin{array}{l}
p_{i j}^{s}, r=i \\
p_{i j}^{s}\left(1+\mathrm{e}^{-k \theta_{i j}^{s}}\right), r \neq i
\end{array}, \quad \theta_{i j}^{s}=\frac{\left(1-w_{r j}\right) z_{i r j}}{\left(\mathrm{Q}_{r j}^{s}-D d_{r} d_{r j}\right)+0.01}, k=1\right.
$$

Subject to:

$$
\begin{array}{r}
\text { St. } d_{L}=\left\{\begin{array}{r}
P Q_{L} / D, D>P Q_{L} \\
1, D \leq P Q_{L}
\end{array}\right. \\
0 \leq d_{i} \leq 1
\end{array}
$$




$$
\sum_{t=1}^{m} y_{i j t} \leq Q_{j t}^{o}
$$

$$
i, r=1,2, \ldots, n ; t=1,2, \ldots, m ; j=1,2
$$

The objective function (4) includes four parts. The first one is the profit of alliance leader, which consists of product sales profit, production costs, costs of the order subcontracted, costs of procurement from private suppliers, costs of cross-chain procurement from private suppliers and costs of procurement from independent suppliers. The second one represents the total profit of all the single supply chains which includes product sales profit, production costs, costs of procurement from private suppliers, costs of cross-chain procurement from private suppliers and costs of procurement from independent suppliers. The third one is the total profits of all the private suppliers which are composed of direct sales profit, cross-chain sales profit and production costs. The last part represents the total profits of all the independent suppliers, which include sales profits from the alliance leader and those 
from other single supply chains. Constraint (5) defines the remained order by the alliance leader for itself. Constraint (6) gives the order subcontracting scope. Constraint (7) represents whether the quantity that the $\mathrm{i}^{\text {th }}$ single supplier chain manufacturer sources from the $\mathrm{j}^{\text {th }}$ private supplier are over the capacity of a private supplier or not. Constraint (8) shows whether the single supply chain $i$ is subcontracted by the alliance leader. Constraint (9) gives the number of single supply chains subcontracted by the alliance leader. Constraint (10) defines the proportion of the $\mathrm{i}^{\text {th }}$ single supply chain manufacturer sourcing from the $\mathrm{j}^{\text {th }}$ private supplier. Constraint (11) represents subcontracting the order proportion satisfying equality condition. Constraints (12) and (13) give manufacturers' sourcing quantity scope from private suppliers and independent suppliers, respectively. Constraint (14) shows subcontracting the order not exceeding the capacity of manufacturers. Constraint (15) represents the quantity satisfying equality condition sourcing from independent suppliers and private suppliers. Constraints (16) and (17) illustrate the quantity scope by sourcing from other private suppliers and independent suppliers, respectively.

5.3 The improved ALC modelling

The coupling relationships among all types of decision elements in the improved ALC model are depicted in Fig.6.

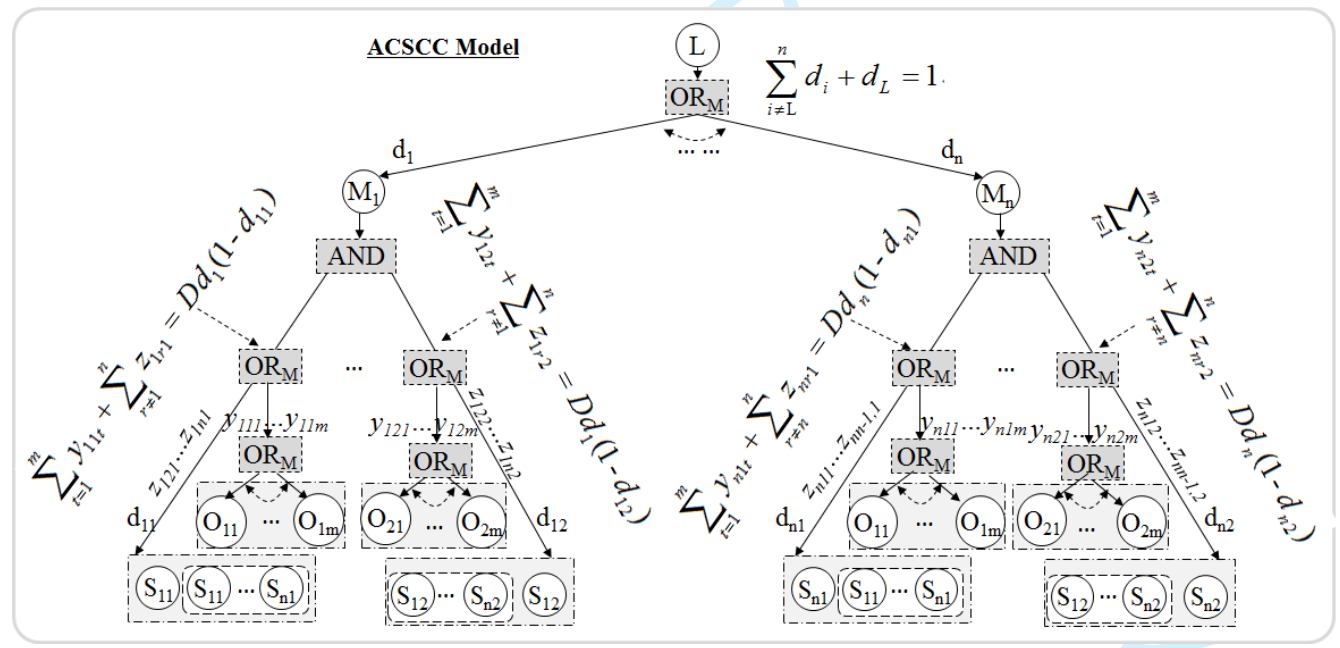

Fig.6. Coupling relationships among the three types of decision elements

As shown in Fig.6, there exist couplings (i.e. the linking variable $d_{i}$ and the constraint $1-\sum_{i \neq L}^{n} d_{i}-d_{L}=0$ ) between the alliance leader element and a single supply chain's 
manufacturer element. Likewise, a single supply chain's private supplier element and an independent supplier element are coupled by the constraint $\sum_{t=1}^{m} y_{i j t}+\sum_{\substack{r \neq i \\ r=1}}^{n} z_{i r j}=D d_{i}\left(1-d_{i j}\right)$, and there's also a linking variable $y_{i j t}$ between the manufacturer and the independent supplier element, the manufacturer and other private suppliers are coupled by the linking variable $z_{i r j}$. According to the coupling relationships, the local decision model of participants in the industrial cluster could be formulated with the improved ALC coordination in the following sections.

\subsubsection{The improved ALC formulation for the alliance leader element}

The alliance leader's decision model is represented by equation (18). The first item is the sales profit. The other items represent the costs of production, the order subcontracting to other single supply chains and sourcing from private or independent suppliers, as well as the relaxed constraints.

$$
\begin{aligned}
& \max _{d, y_{1}, y_{2}, z_{1}, z_{2}} P f_{M_{L}}=p D-D d_{L} c_{L}-\sum_{i \neq L}^{n} D d_{i}\left\lfloor p_{i}\left(1-0.5 d_{i}\right)\right\rfloor-\sum_{j=1}^{2} D d_{L} d_{L j} p_{L j}^{s}- \\
& \sum_{j=1}^{2}\left(\sum_{r \neq L}^{n} z_{L r j} p_{r j}^{s}+\sum_{t=1}^{m} y_{L j t}\left\lfloor p_{j t}^{o}\left(1-\frac{y_{L j t}}{2 Q_{j t}^{o}}\right)\right\rfloor\right)-\varphi\left(h_{0}\right)-\sum_{j=1}^{2} \varphi\left(h_{L j}\right)- \\
& \sum_{j=1}^{2}\left(\sum_{t=1}^{m} \varphi\left(y_{L j t}\right)-\sum_{r \neq L}^{n} \varphi\left(z_{L r j}\right)\right)-\sum_{i \neq L}^{n} \varphi\left(d_{i}\right)-\sum_{j=1}^{2} \varphi\left(d_{L j}\right)
\end{aligned}
$$

Where $d=\left[d_{1}, d_{2}, \ldots d_{L}, \ldots, d_{n}, d_{L 1}, d_{L 2}\right], y_{1}=\left[y_{L 11}, y_{L 12}, \ldots, y_{L 1 m}\right], y_{2}=\left[y_{L 21}, y_{L 22}, \ldots, y_{L 2 m}\right]$ $z_{1}=\left[z_{L 11}, z_{L 21}, z_{L 31}, \ldots, z_{L n 1}\right], z_{2}=\left[z_{L 21}, z_{L 22}, z_{L 32}, \ldots, z_{L n 2}\right]$

The constraints are the followings.

$$
\begin{gathered}
d_{L}=\left\{\begin{array}{l}
P Q_{L} / D, D>P Q_{L} \\
1, D \leq P Q_{L}
\end{array}\right. \\
0 \leq d_{i} \leq 1
\end{gathered}
$$


Couplings are relaxed as follows.

$$
\begin{gathered}
\varphi\left(y_{L j t}\right)=v_{y L j t}\left(y_{L j t}-y_{L j t}^{l}\right)+\left\|w_{y L j t} \circ\left(y_{L j t}-y_{L j t}^{l}\right)\right\|_{2}^{2} \\
\varphi\left(z_{L r j}\right)=v_{z L r j}\left(z_{L r j}-z_{L r j}^{l}\right)+\left\|w_{z L r j} \circ\left(z_{L r j}-z_{L r j}^{l}\right)\right\|_{2}^{2} \\
\varphi\left(d_{i}\right)=v_{d i}\left(\mathrm{~d}_{\mathrm{i}}-d_{i}^{l}\right)+\left\|\mathrm{w}_{d i} \circ\left(\mathrm{d}_{\mathrm{i}}-d_{i}^{l}\right)\right\|_{2}^{2} \\
\varphi\left(d_{L j}\right)=v_{d L j}\left(d_{L j}-d_{L j}^{l}\right)+\left\|w_{d L j} \circ\left(d_{L j}-d_{L j}^{l}\right)\right\|_{2}^{2} \\
\varphi\left(h_{0}\right)=v_{h 0} h_{0}+\left\|\mathrm{w}_{h 0} \circ h_{0}\right\|_{2}^{2} \\
\varphi\left(h_{L j}\right)=v_{h L j} h_{L j}+\left\|w_{h L j} \circ h_{L j}\right\|_{2}^{2}
\end{gathered}
$$

The meanings of constraints (19) to (27) are the same as those in the AIO model of ACSCC. Equations (28) and (29) are the relaxation of sourcing constraints, $y_{L j t}^{l}$ and $z_{L r j}^{l}$ are the backtrack values from upstream independent suppliers and other private suppliers to the alliance leader, respectively, and $v_{y L j t}, v_{z L r j}, w_{y L j t}$ and $w_{z L r j}$ are the relaxation parameters. Equation (30) represents the constraint coupling relaxation of order subcontracting ratio, where $d_{i}^{l}$ is the backtrack value from subcontracting single supply chains to the alliance leader, and $v_{d i}, w_{d i}$ are the relaxation parameters. Equation (31) represents the constraint coupling relaxation of order sourcing ratio, where $d_{L j}^{l}$ is the backtrack value from the $j^{\text {th }}$ private supplier to the alliance leader, and $v_{d L j}, w_{d L j}$ are the relaxation parameters. Equations (32) and (33) are the coupling relaxation of equality constraints, 
and $v_{h 0}, v_{h L j}, w_{h 0}$ and $w_{h L j}$ are the relaxation parameters.

5.3.2 The improved ALC formulation for manufacturer decision element

The manufacturer's decision model is represented by equation (34). The first item is the sales profit of the single supply chain, while other items represent the costs of production and sourcing, as well as the constraints relaxation.

$$
\begin{aligned}
& \max _{d, y_{1}, y_{2}, z_{1}, \mathrm{z}_{2}} P f_{M_{i}}=D d_{i}\left\lfloor p_{i}\left(1-0.5 d_{i}\right)\right\rfloor-D d_{i} c_{i}-\sum_{j=1}^{2} D d_{i} d_{i j} p_{i j}^{s}- \\
& \sum_{j=1}^{2}\left(\sum_{r \neq i}^{n} z_{i r j} p_{r j}^{s}+\sum_{t=1}^{m} y_{i j t}\left\lfloor p_{j t}^{o}\left(1-\frac{y_{i j t}}{2 \mathrm{Q}_{j t}^{o}}\right)\right\rfloor\right)-\varphi\left(h_{0}\right)-\sum_{j=1}^{2} \varphi\left(h_{i j}\right)- \\
& {\left[\sum_{j=1}^{2}\left(\sum_{t=1}^{m} \varphi\left(y_{i j t}\right)+\sum_{r \neq i}^{n} \varphi\left(z_{i r j}\right)\right)+\varphi\left(d_{i}\right)+\sum_{j=1}^{2} \varphi\left(d_{i j}\right)\right]}
\end{aligned}
$$

Where $d=\left[d_{i}, d_{i 1}, d_{i 2}\right] y_{1}=\left[y_{i 11}, y_{i 12}, \ldots, y_{i 1 m}\right], y_{2}=\left[y_{i 21}, y_{i 22}, \ldots, y_{i 2 m}\right], z_{1}=\left[z_{i 21}, z_{i 31}, \ldots, z_{i n 1}\right]$, $z_{2}=\left[z_{i 22}, z_{i 32}, \ldots, z_{i n 2}\right]$

The constraints are the followings.

$$
\begin{gathered}
h_{0}=1-\sum_{i \neq L}^{n} d_{i}-d_{L}=0 \\
D d_{i} \leq P Q_{i},(i \neq L) \\
0 \leq d_{i}<1 \\
w_{i j}=\left\{\begin{array}{c}
1, D d_{i} \geq Q_{i j}^{s} \\
0, D d_{i}<Q_{i j}^{s}
\end{array}\right. \\
d_{i j}=\frac{w_{i j} Q_{i j}^{s}}{D d_{i}}+1-w_{i j} \\
h_{i j}=\sum_{t=1}^{m} y_{i j t}+\sum_{r \neq i}^{n} z_{i r j}-D d_{i}\left(1-d_{i j}\right)=0 \\
0 \leq Q_{i j t}^{s} \leq Q_{j t}^{o}
\end{gathered}
$$

Couplings are relaxed as follows.

$$
\varphi\left(y_{i j t}\right)=v_{y i j t}\left(y_{i j t}-y_{i j t}^{l}\right)+\left\|w_{y i j t} \circ\left(y_{i j t}-y_{i j t}^{l}\right)\right\|_{2}^{2}
$$




$$
\varphi\left(z_{i r j}\right)=v_{z i r j}\left(z_{i r j}-z_{i r j}^{l}\right)+\left\|w_{z i r j} \circ\left(z_{i r j}-z_{i r j}^{l}\right)\right\|_{2}^{2}
$$

$$
\varphi\left(d_{i}\right)=v_{d i}\left(\mathrm{~d}_{\mathrm{i}}-d_{i}^{u}\right)+\left\|\mathrm{w}_{d i} \circ\left(\mathrm{d}_{\mathrm{i}}-d_{i}^{u}\right)\right\|_{2}^{2}
$$$$
\varphi\left(d_{i j}\right)=v_{d i j}\left(d_{i j}-d_{i j}^{l}\right)+\left\|w_{d i j} \circ\left(d_{i j}-d_{i j}^{l}\right)\right\|_{2}^{2}
$$$$
\varphi\left(h_{0}\right)=v_{h 0} h_{0}+\left\|\mathrm{w}_{h 0} \circ h_{0}\right\|_{2}^{2}
$$

$$
\varphi\left(h_{i j}\right)=v_{h i j} h_{i j}+\left\|w_{h i j} \circ h_{i j}\right\|_{2}^{2}
$$

The meanings of constraints (35) to (42) are the same as those in the AIO model of ACSCC. Constraint (43) is the relaxation of sourcing quantity, where $y_{i j t}^{l}$ is the backtrack value from upstream independent suppliers to the manufacturer, $v_{y i j t}, w_{y i j t}$ are the relaxation parameters. Constraint (44) is the relaxation of sourcing quantity, where $z_{i r j}^{l}$ is the backtrack value from other private suppliers to the manufacturer, $v_{z i r j}, w_{z i r j}$ are the relaxation parameters. Equation (45) represents the constraint coupling relaxation of order subcontract ratio, where $d_{i}^{u}$ is the backtrack value from subcontracting single supply chains to the manufacturer, and $v_{d i}, w_{d i}$ are the relaxation parameters. Equation (46) represents the constraint coupling relaxation of order sourcing ratio, where $d_{i j}^{l}$ is the backtrack value from the $j^{\text {th }}$ private supplier to the manufacturer, and $v_{d i j}, w_{d i j}$ are the relaxation parameters. Equations (47) and (48) are the coupling relaxation of equality constraints, and $v_{h 0}, v_{h L j}, w_{h 0}, w_{h L j}$ are the relaxation parameters.

\subsubsection{The improved ALC formulation for independent supplier decision element}

The objective of the independent supplier $t$ of component $j$ is shown by equation (49). The first item is the sales profit of the independent supplier $t$ of component $j$, while other items represent the sourcing cost and the constraints relaxation respectively.

$$
\max _{y_{j}} P f_{S O}=\sum_{i=1}^{n} y_{i j t}\left(\left\lfloor p_{j t}^{o}\left(1-\frac{y_{i j t}}{2 Q_{j t}^{o}}\right)\right\rfloor-\mathrm{c}_{j t}^{o}\right)-\varphi\left(h_{i j}\right)-\sum_{i=1}^{n} \varphi\left(y_{i j t}\right)
$$

Where $y_{j}=\left[y_{1 j t}, y_{2 j t}, \ldots, y_{n j t}\right]$

The constraints are the followings. 


$$
\begin{gathered}
0 \leq y_{i j t} \leq Q_{j t}^{o} \\
h_{i j}=\sum_{t=1}^{m} y_{i j t}+\sum_{r \neq i}^{n} z_{i r j}-D d_{i}\left(1-d_{i j}\right)=0
\end{gathered}
$$

Couplings are relaxed as follows.

$$
\begin{array}{r}
\varphi\left(y_{i j t}\right)=v_{y j j t}\left(y_{i j t}-y_{i j t}^{u}\right)+\left\|w_{y j i t} \circ\left(y_{i j t}-y_{i j t}^{u}\right)\right\|_{2}^{2} \\
\varphi\left(h_{i j}\right)=v_{h i j} h_{i j}+\left\|w_{h i j} \circ h_{i j}\right\|_{2}^{2}
\end{array}
$$

The meanings of constraints (50) to (51) are the same as those in the AIO model of ACSCC. Equation (52) represents the coupling relaxation of the sourcing quantity, where $y_{i j t}^{u}$ is the sourcing quantity from independent suppliers by the manufacturer, and $v_{y i j t}, w_{y i j t}$ are the relaxation parameters. Equation (53) is the coupling relaxation of equality constraints, and $v_{h i j}, w_{h i j}$ are the relaxation parameters.

5.3.4 The improved ALC formulation for private supplier decision element

The objective of private supplier $i$ of the component $j$ is shown by equation (54). The former two items are the sales profit of private supplier $i$ of the component $j$, while other items represent the sourcing cost and the constraints relaxation, respectively.

$$
\max _{d z} P f_{S}=D d_{i} d_{i j}\left(p_{i j}^{s}-c_{i j}^{s}\right)+\sum_{r \neq i}^{n} z_{r i j}\left(p_{r j}^{s}-c_{r j}^{s}\right)-\varphi\left(h_{i j}\right)-\sum_{r \neq i}^{n} \varphi\left(z_{r i j}\right)-\varphi\left(d_{i j}\right)
$$

Where $d z=\left[d_{i j}, z_{1 i j}, z_{2 i j}, \ldots, z_{n i j}\right]$

The constraints are the followings.

$$
\begin{aligned}
& w_{i j}=\left\{\begin{array}{l}
1, D d_{i} \geq Q_{i j}^{s} \\
0, D d_{i}<Q_{i j}^{s}
\end{array}\right. \\
& d_{i j}=\frac{w_{i j} Q_{i j}^{s}}{D d_{i}}+1-w_{i j} \\
& h_{i j}=\sum_{t=1}^{m} y_{i j t}+\sum_{r \neq i}^{n} z_{i r j}-D d_{i}\left(1-d_{i j}\right)=0 \\
& \sum_{r \neq i}^{n} z_{r i j}+D d_{i} d_{i j}\left(1-w_{i j}\right) \leq Q_{i j}^{s}\left(1-w_{i j}\right) \\
& 0 \leq z_{r i j} \leq Q_{i j}^{s}
\end{aligned}
$$


Couplings are relaxed as follows.

$$
\begin{array}{r}
\varphi\left(z_{r i j}\right)=v_{z r i j}\left(z_{r i j}-z_{r i j}^{u}\right)+\left\|w_{z r i j} \circ\left(z_{r i j}-z_{r i j}^{u}\right)\right\|_{2}^{2} \\
\varphi\left(d_{i j}\right)=v_{d i j}\left(d_{i j}-d_{i j}^{u}\right)+\left\|w_{d i j} \circ\left(d_{i j}-d_{i j}^{u}\right)\right\|_{2}^{2} \\
\varphi\left(h_{i j}\right)=v_{h i j} h_{i j}+\left\|w_{h i j} \circ h_{i j}\right\|_{2}^{2}
\end{array}
$$

The meanings of constraints (55) to (59) are the same as those in the AIO model of ACSCC. Equation (60) represents the coupling relaxation of the sourcing quantity, where $z_{r i j}^{u}$ is the sourcing quantity from other private suppliers by the manufacturer, and $v_{z r i j}, w_{z r i j}$ are the relaxation parameters. Equation (61) denotes the constraint coupling relaxation of the order sourcing ratio, where $d_{i j}^{u}$ is the backtrack value from the private $j$ to the manufacturer, and $v_{d i j}, w_{d i j}$ are the relaxation parameters. Equation (62) is the coupling relaxation of equality constraints, and $v_{h i j}, w_{h i j}$ are the relaxation parameters.

\section{The improved ALC solution}

The numeric results are analysed in this section. Before the improved ALC method is confidently used for ACSCC, a geometric programming problem (GPP) will be solved using the improved ALC. Through the application of the improved ALC to solve GPP, we will find out whether the master problem is created artificially or by making use of an existing sub-problem in the ALC method, and a comparison of the improved ALC method and the centralized ALC method indicates how well the improved ALC works for the ACSCC problem.

6.1 Geometric programming problem

GPP is derived from the literature (Kim et al. 2003), given by:

$$
\begin{gathered}
\min _{x_{1}, \cdots, x_{14}} f=f_{1}+f_{2}=x_{1}^{2}+x_{2}^{2} \\
\text { s.t. } \quad x_{1}, \cdots, x_{14} \geq 0 \\
g_{1}=\left(x_{3}^{-2}+x_{4}^{2}\right) x_{5}^{-2}-1 \leq 0 \quad g_{2}=\left(x_{5}^{2}+x_{6}^{-2}\right) x_{7}^{-2}-1 \leq 0, \\
g_{3}=\left(x_{8}^{2}+x_{9}^{2}\right) x_{11}^{-2}-1 \leq 0, \quad g_{4}=\left(x_{8}^{-2}+x_{10}^{2}\right) x_{11}^{-2}-1 \leq 0 \\
g_{5}=\left(x_{11}^{2}+x_{12}^{-2}\right) x_{13}^{-2}-1 \leq 0, \quad g_{6}=\left(x_{11}^{2}+x_{12}^{2}\right) x_{14}^{-2}-1 \leq 0 \\
h_{1}=\left(x_{3}^{2}+x_{4}^{-2}+x_{5}^{2}\right) x_{1}^{-2}=1, \quad h_{2}=\left(x_{5}^{2}+x_{6}^{2}+x_{7}^{2}\right) x_{2}^{-2}=1 \\
h_{3}=\left(x_{8}^{2}+x_{9}^{-2}+x_{10}^{-2}+x_{11}^{2}\right) x_{3}^{-2}=1, h_{4}=\left(x_{11}^{2}+x_{12}^{2}+x_{13}^{2}+x_{14}^{2}\right) x_{6}^{-2}=1
\end{gathered}
$$


As shown in Fig.7 (a), the standard problem is partitioned into four sub-problems, $\mathrm{P}_{1}, \mathrm{P}_{2}, \mathrm{P}_{3}$, and $\mathrm{P}_{4}$, based on the variable relationships given in equality constraints and inequality constraints (Tosserams et al. 2007). Here, the distributed ALC, the centralized ALC, and the improved ALC are applied on this GPP. The distributed ALC directly uses the problem partition, while the centralized ALC artificially creates a master problem $\mathrm{P}_{0}$ to coordinate all the sub-problems $\left(\mathrm{P}_{1}, \mathrm{P}_{2}, \mathrm{P}_{3}\right.$, and $\left.\mathrm{P}_{4}\right)$, as shown in Fig. 7(b). The improved ALC selects an existing sub-problem to coordinate other sub-problems according to the selection principle above, because of the same links among the sub-problems. We might as well select the sub-problems $\mathrm{P}_{1}$, as shown in Fig.8.

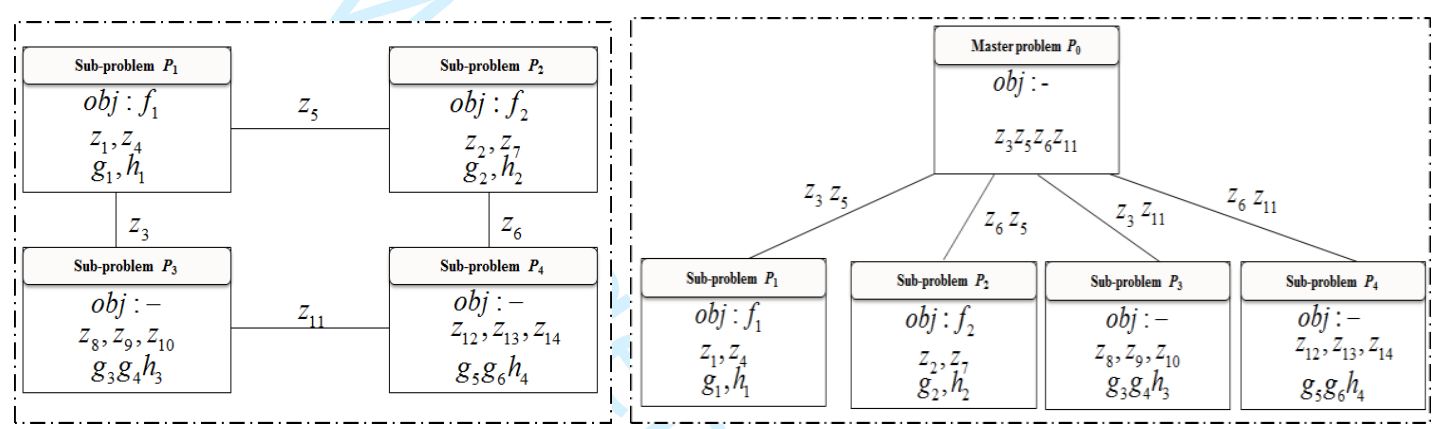

(a) Decomposition model of GPP

(b) Decomposition model of centralized ALC for GPP

Fig. 7 Decomposition structure model of GPP and Decomposition structure model of centralized ALC for GPP

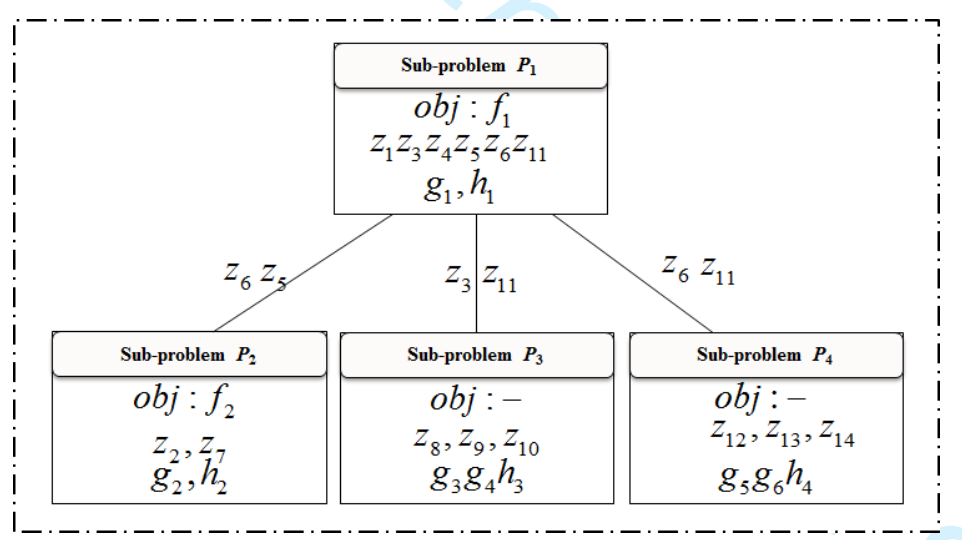

Fig.8 Decomposition model of the improved ALC for GPP

The simulation of each coordination method is conducted by Matlab7.11 in a PC with $2.5 \mathrm{GHz} \mathrm{CPU}$ and 4GB RAM, which uses the interior point as the default algorithm. We have $\beta=2.2, \gamma=0.4$, $\alpha_{0}=0.1$, tolerance $\varepsilon=0.001$, the maximum iterations of outer and inner loop are set to 1000 and 10 respectively. The initial values of penalty factors $v, w$ are both set to 1 . The GPP design variables of the actual value of the optimal solution 


$$
\left(x_{1}, x_{2}, x_{3}, x_{4}, x_{5}, x_{6}, x_{7}, x_{8}, x_{9}, x_{10}, x_{11}, x_{12}, x_{13}, x_{14}\right)=(2.8354,3.0902,2.3559,0.7598,0.8704
$$

$2.8120,0.9402,0.9719,0.8651,0.7965,1.3012,0.8408,1.7628,1.5492)$, Objective function value is

17.5887. The consistency constraints of three methods change with each iteration of the loop as shown in Fig. 9 (a), (b), (c), respectively. The comparative results with three methods are given in Table 3.

Table 3 Results comparison among three coordination methods for GPP

\begin{tabular}{lcccc}
\hline \multicolumn{1}{c}{ Method } & $\begin{array}{c}\text { Outer loop } \\
\text { iterations }\end{array}$ & $\begin{array}{c}\text { Number of coupling } \\
\text { variables }\end{array}$ & ER & $\begin{array}{l}\text { Objective Function } \\
\text { Value }\end{array}$ \\
\hline Centralize ALC & 38 & 8 & $3.3707 \times 10^{-4}$ & 17.5961 \\
Improved ALC & 34 & 6 & $3.2755 \times 10^{-4}$ & 17.5957 \\
Distributed ALC & 32 & 4 & $3.3842 \times 10^{-4}$ & 17.5973 \\
\hline
\end{tabular}

In Table 3, the RE of error results is defined as: $E R=\sqrt{\frac{\left\|x-x_{0}\right\|_{2}^{2}}{\left\|x_{0}\right\|_{2}^{2}}},\|\cdot\|_{2}^{2}$ is Paradigm of $l_{2}, x$ is the vector of the optimal solution, $x_{0}$ is the vector of the actual reference value of the optimal solution.

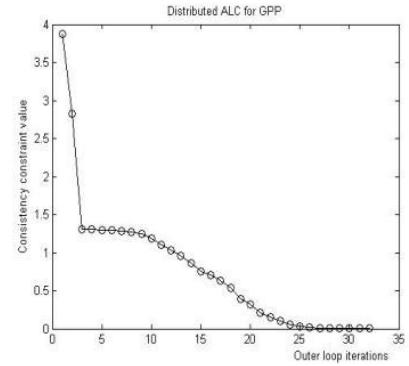

(a)Distributed ALC for GPP

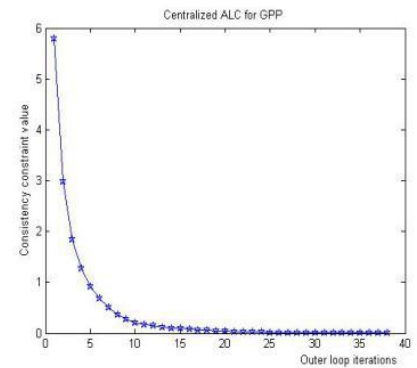

(b) Centralized ALC for GPP

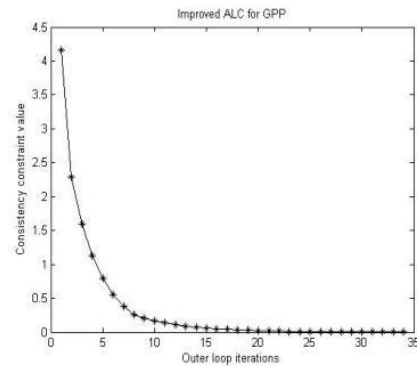

(c) Improved ALC for GPP

Fig.9 The change process of consistency constraints with outer loop iterations using three kinds of coordination of ALC for GPP

From Table 3, it is obvious that the distributed ALC achieves highest efficiency within the least number of iterations (32) among the three coordination methods. For the centralized ALC with an artificial master problem, the number of iterations is 38 , which is more than those of the distributed ALC and improved ALC. The number of iterations of the improved ALC is between those of distributed ALC and centralized ALC. While the ER values of the centralized, the distributed and the improved ALC are $3.3707 \times 10^{-4}, 3.2755 \times 10^{-4}, 3.3842 \times 10^{-4}$ respectively, which are all very small. Thus, the accuracy of the three coordination methods is about the same. Meanwhile, comparison results among three-coordination methods show the number of copies of linking variables plays an important 
role when determining the performance of a coordination strategy, which is also illustrated in Fig.9. The number of copies increases in the order of three coordination methods (distributed ALC, improved ALC and centralized ALC), and so does the parallelism of the three methods, while the efficiency decreases in the order of those. Centralized ALC sacrifices efficiency in exchange for the parallel computation of sub-problems. The introduction of an existing sub-problem in the improved ALC not only enables all sub-problems to be optimized in parallel but also improves the efficiency of the centralize ALC. Therefore, the improved ALC is the best coordination method considering the balance of parallelism, accuracy and efficiency.

6.2 The improved ALC for the problem of ACSCC

The above sub-section has illustrated the accuracy and efficiency of the improved ALC through the GPP. This sub-section uses it to solve the problem of ACSCC. We select the alliance leader $M_{1}$ (as the master problem) to be responsible for coordinating other decision elements according to the selection principle above, and set the number of single supply chains in the cluster as $n=5$, and the number of independent suppliers $m=3$, The product alliance leader takes the order as $D=1000$, while other parameters are shown in Table 4 , where $i, r=1,2,3,4,5, j=1,2$.

Table 4 Parameters setting

\begin{tabular}{lccc}
\hline Parameters & Parameters values & Parameters & Parameters values \\
\hline$c_{i}$ & $6 \$, 7 \$, 9 \$, 8 \$, 5 \$$ & $p$ & $98 \$$ \\
$P Q_{i}$ & $720,980,790,960,840$ & $p_{i}$ & $30 \$, 25 \$, 32 \$, 36 \$, 24 \$$ \\
& 520,450 & & $9 \$, 10 \$$ \\
$Q_{i j}^{s}$ & 470,440 & & $7 \$, 12 \$$ \\
& 530,600 & $p_{i j}^{s}$ & $8 \$, 7 \$$ \\
& 350,570 & & $6 \$, 11 \$$ \\
$p_{j t}^{o}$ & 440,330 & & $5 \$, 10 \$$ \\
& $12 \$, 9 \$$ & & 442,450 \\
& $8 \$, 8 \$$ & $Q_{j t}^{o}$ & 441,440 \\
& $10 \$, 13 \$$ & & 454,432 \\
$c_{i j}^{s}$ & $6 \$, 8 \$$ & & $5 \$, 3 \$$ \\
& $5 \$, 9 \$$ & $c_{j t}^{o}$ & $2 \$, 2 \$$ \\
& $4 \$, 3 \$$ & & $4 \$, 6 \$$ \\
\hline
\end{tabular}

The initial values set for parameters in the improved ALC method are as follows.

$\beta=2.2, \gamma=0.4, \alpha=0.1$, tolerance $\varepsilon=0.001$, the maximum iteration times of outer and inner 
loop are also set to 10000 and 10 respectively. The initial values of penalty factors $v, w$ are both set to 1 . The initial parameters $d_{1}^{l}, d_{2}^{l}, d_{3}^{l}, d_{4}^{l}, d_{5}^{l}$ and $d_{11}^{l}, d_{12}^{l}, d_{21}^{l}, d_{31}^{l}, d_{32}^{l}, d_{41}^{l}, d_{42}^{l}, d_{51}^{l}, d_{52}^{l}$ are set randomly between 0 and 1 . Initial parameters $y_{i 1 t}^{l}, y_{i 2 t}^{l}, z_{i r 1}^{l}$ and $z_{i r 2}^{l}$ are given by:

$$
\begin{gathered}
{\left[y_{i 1 t}^{l}\right]=\left[\begin{array}{l}
y_{111}^{l}, y_{112}^{l}, y_{113}^{l} \\
y_{211}^{l}, y_{212}^{l}, y_{213}^{l} \\
y_{311}^{l}, y_{312}^{l}, y_{313}^{l} \\
y_{411}^{l}, y_{412}^{l}, y_{413}^{l} \\
y_{511}^{l}, y_{512}^{l}, y_{513}^{l}
\end{array}\right]=\left[\begin{array}{l}
1,1,1 \\
0,0,0 \\
0,0,0 \\
0,0,0 \\
0,0,0
\end{array}\right],\left[y_{i 2 t}^{l}\right]=\left[\begin{array}{l}
y_{121}^{l}, y_{122}^{l}, y_{123}^{l} \\
y_{221}^{l}, y_{222}^{l}, y_{223}^{l} \\
y_{321}^{l}, y_{322}^{l}, y_{323}^{l} \\
y_{421}^{l}, y_{422}^{l}, y_{423}^{l} \\
y_{521}^{l}, y_{522}^{l}, y_{523}^{l}
\end{array}\right]=\left[\begin{array}{l}
0,200,0 \\
0,0,0 \\
0,0,0 \\
0,0,0 \\
0,0,0
\end{array}\right]} \\
{\left[\begin{array}{l}
\left.z_{i r 1}^{l}\right] \\
z_{121}^{l}, z_{131}^{l}, z_{141}^{l}, z_{151}^{l} \\
z_{211}^{l}, z_{231}^{l}, z_{241}^{l}, z_{251}^{l} \\
z_{311}^{l}, z_{321}^{l}, z_{341}^{l}, z_{351}^{l} \\
z_{411}^{l}, z_{421}^{l}, z_{431}^{l}, z_{451}^{l} \\
z_{511}^{l}, z_{521}^{l}, z_{531}^{l}, z_{541}^{l}
\end{array}\right]=\left[\begin{array}{l}
0,0,100,40 \\
0,0,0,0 \\
0,0,0,0 \\
0,0,0,0 \\
0,0,0,0
\end{array}\right],\left[\begin{array}{l}
z_{122}^{l}, z_{132}^{l}, z_{142}^{l}, z_{152}^{l} \\
z_{212}^{l}, z_{232}^{l}, z_{242}^{l}, z_{252}^{l} \\
z_{312}^{l}, z_{322}^{l}, z_{342}^{l}, z_{352}^{l} \\
z_{412}^{l}, z_{422}^{l}, z_{432}^{l}, z_{452}^{l} \\
z_{512}^{l}, z_{522}^{l}, z_{532}^{l}, z_{542}^{l}
\end{array}\right]=\left[\begin{array}{l}
0,0,0,0 \\
0,0,0,0 \\
0,0,0,0 \\
0,0,0,0 \\
0,0,0,0
\end{array}\right]}
\end{gathered}
$$

The initial values of other relaxation parameters are all set to 1.

\subsection{Experiment Simulation}

The simulation is also conducted by Matlab7.11 in a PC with 2.5GHz CPU and 4GB RAM, which uses the interior point as the default algorithm to solve sub-problems. The comparative results with Lingo11 are given in the appendix (Table 5). As can be seen from Table 5, the alliance leader selects single supply chains 1 and 5 , with the order allocation ratio as $0.72,0.28$, respectively, and it sources the quantity exceeding its own private suppliers' capacity from independent suppliers of component 2 and other private suppliers of component 1 . Thus, the independent supplier $O_{22}$ of component 2 and private suppliers $\left(S_{41}, S_{51}\right)$ are selected respectively by the alliance leader, with sourcing quantity as $269.89,149.60,50.40$, respectively by the improved ALC method, with that as $269.96,149.92,50.08$, respectively by the centralized ALC method, and with that as $270,150,50$ by Lingo11. The formation of the optimal ACSCC is shown in Fig.10. Meanwhile, computational time of the three methods (i.e., Lingo11, improved ALC and centralized ALC) is 29.82(min), 12.43(min) and 14.53 (min), respectively. Therefore, experimental results comparison shows that the computational accuracy of the improved ALC method almost as identical as Lingo11, while Lingo11 offers much longer optimization time. It 
also illustrates that the efficiency of the improved ALC is significantly better than that of the centralized ALC.

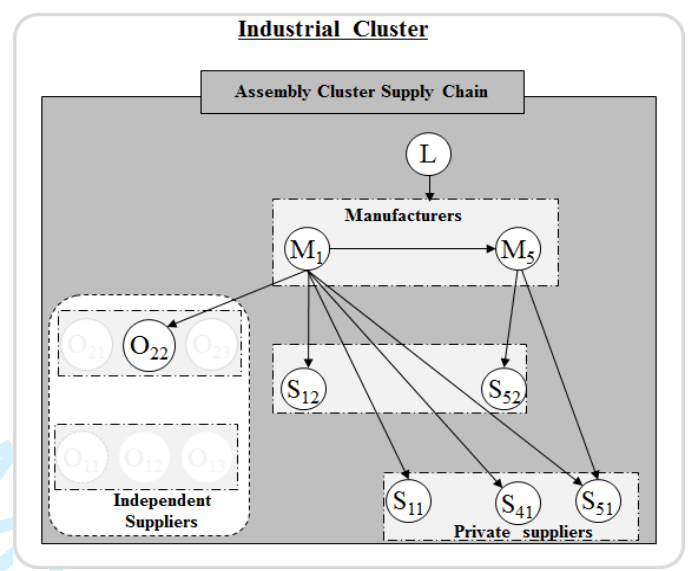

Fig.10 Formation of the optimal ACSCC

\subsection{Sensitivity analysis}

In this subsection, sensitivity analysis of various parameters (such as the order's quantity change, the sale price of independent suppliers change) is performed to investigate their change on the ACSCC. 6.4.1 The sensitivity analysis of the order change

We analyse the impact of the order's quantity change on ACSCC results. Obviously, if the order that the alliance leader receiving is small, $M_{1}$ 's single supply chain (i.e. $M_{1}-S_{11}, M_{1}-S_{12}$ ) is adequate. While if the order is large, the alliance leader has to select cooperative single supply chains and suppliers to configure an ACSC to finish the order production. In order to answer the questions under what conditions a manufacturer recourses to CSC and what the most suitable ACSCC is, related sensitivity analysis is done as followings.

First, if the order quantity taken by $\mathrm{M}_{1}$ does not exceed its private suppliers' capacity and $\mathrm{M}_{1}$ 's capacity, namely not more than $450, \mathrm{M}_{1}$ own supply chain is enough to fulfil the order.

Second, if $450<D \leq 720$, that is, the order quantity is less than $\mathrm{M}_{1}$ 's production capacity, while its private suppliers cannot satisfy the resulted component requirement, $\mathbf{M}_{1}$ becomes an alliance leader, and sources from independent suppliers or other private suppliers of other single supply chains through multiple sourcing strategy. The formation of the optimal ACSCC of this case belongs to the third basic form of CSC, as shown in Fig. 2(c).

(1) If $450<D \leq 520$, the order quantity is less than the capacity of the private of component 1 and exceeds the capacity of the private of component 2 , for example $D=500, \mathrm{M}_{1}$ sources from the 
independent supplier $O_{22}$ of component 2, and the sourcing quantity is 50 .

(2) If $520<D<700$, for example $D=600$, the order quantity exceeds the capacity of the private of component 1 and $2, \mathrm{M}_{1}$ becomes an alliance leader, and sources from the independent supplier $O_{22}$ of component 2 , and the sourcing quantity is 150 . In addition, $\mathrm{M}_{1}$ cross-chain sources from the private supplier $S_{14}$, and the sourcing quantity is 80 .

(3) If $700 \leq D \leq 720$, e.g. $D=710$, the order quantity also exceeds the capacity of the private of component 1 and $2, \mathrm{M}_{1}$ becomes an alliance leader, and sources from independent suppliers $\left(0_{12}, O_{12}\right)$ of component 1 and 2, with the sourcing quantity as 190,260, respectively.

Third, if the order quantity exceeds $M_{1}$ 's production capacity while is still not more than the cluster's total capacity, $\mathrm{M}_{1}$ will become an alliance leader, and subcontract a portion of the order to other single supply chain(s), meanwhile, source from independent suppliers or other private suppliers of other single supply chains. Based on the subcontracting order quantity, manufacturers of other single supply chains adopt different sourcing strategies such as cross-chain sourcing or multiple sourcing from independent suppliers outside. For example, $D=1050, \mathrm{M}_{1}$ becomes an alliance leader and subcontracts a portion of the order to single supply chain 5, and sources from the independent supplier $O_{22}$ of component 2, with the sourcing quantity as 270 . In addition, $\mathrm{M}_{1}$ cross-chain sources from the private supplier $S_{41}$ of component 1 , and the sourcing quantity is 200 . The formation of the optimal ACSCC of this case belongs to the fourth combination form of CSC, as shown in Fig.2 (d). Meanwhile, the changing curves of the maximum profit of the CSC system, the maximum profit of the alliance leader $\left(P f_{M_{L}}\right)$ and the sum of the maximum profit of private suppliers ( $\left.\operatorname{SumPf} f_{S}\right)$, the sum of the maximum profit of independent suppliers $\left(\operatorname{SumPf_{SO}}\right)$, the sum of the maximum profit of subcontracted single supply chains suppliers ( $\operatorname{SumPf}_{M_{\mathrm{i}}}$ ) are given in Fig.11, respectively. 
It shows that the maximum profit of the CSC system and the alliance leader $\left(P f_{M_{L}}\right)$ almost increase linearly with the order $D$, and the sum of the maximum profit of private suppliers ( $\operatorname{SumPf} f_{S}$ ) is growing relatively slowly with the increase of the order $D$, as shown in Fig.11 (a).

As can be seen in Fig.11 (b), the sum of the maximum profit of independent suppliers ( $\operatorname{SumPf} f_{S O}$ ) fluctuates greatly with the increase of the order $D$. If $D \leq 720, \operatorname{SumPf_{SO}}$ increases with the order $D$, and if $720<D \leq 750, \operatorname{SumPf}_{\text {SO }}$ reduces with the order $D$ because the alliance leader subcontracts a portion of the order to single supply chain(s). If $750<D \leq 1050, \operatorname{SumPf}_{\text {SO }}$ remains the same, which illustrates that the alliance leader sourcing quantity from independent suppliers remains constant. If $D>1050$, the subcontracted order exceeds the private supplier's 
capacity of the subcontracted manufacturer, so the subcontracted manufacturer sources from independent suppliers, which results in the growth of $\operatorname{SumPf}_{S O}$. Meanwhile, Fig.11 (b) shows that the sum of the maximum profit of subcontracted single supply chains ( $\operatorname{SumPf} f_{M_{\mathrm{i}}}$ ) increases steadily if $720<D \leq 900$.With the increase of the subcontracted order, SumPf M $_{\mathrm{i}}$ shrinks because subcontracted manufacturers adopt quantity discount policy, which makes their profits in fall gradually. 6.4.2 The sensitivity analysis of the selling price change.

Here, we analyse the influence of the independent supplier's selling price change on cluster supply chain configuration results.

When independent suppliers have to raise the sales price of the unit product, which increases by $2 \$$ on the original basis due to purchasing costs rose, optimal results of ACSCC are as shown in the appendix (Table 6) if the order quantity is $D=1000$ and other parameters remain the same. Table 6 shows that the maximum profit of the alliance leader $\left(P f_{M_{L}}\right.$ ) decreases, while $\mathrm{SumPf}$ increases and $\operatorname{SumPf}_{M_{\mathrm{i}}}$ remains the same. Especially, $\operatorname{SumPf_{SO}}$ is reduced to 0. Meanwhile, it illustrates that the alliance leader, instead of sourcing from the independent suppliers, cross-chain sourced from private suppliers $\left(S_{32}, S_{41}, S_{51}\right)$, and the sourcing quantity is $270,149.60,50.40$ respectively. Other variables remain the same. In addition, it shows that the rising of raw material costs of the market is extremely detrimental to independent suppliers. The formation of the optimal ACSCC of this case belongs to the first combination form of CSC, as shown in Fig.2 (a).

When independent suppliers reduce the sales price of the unit product, which falls $2 \$$ on the original basis due to lower raw material costs, optimal results of ACSCC are as shown in the appendix (Table 7) if the order quantity is $D=1000$ and other parameters remain the same. Table 7 shows that the maximum profit of the alliance leader $\left(P f_{M_{L}}\right)$ increases, while $\operatorname{SumPf_{S}}$ decreases and $\operatorname{SumPf}_{M_{\mathrm{i}}}$ remains the same. Especially, SumPf $f_{S O}$ increases significantly. Meanwhile, it illustrates that the alliance leader, instead of cross-chain sourcing from other private suppliers, sourced from independent suppliers $\left(\mathrm{O}_{12}, \mathrm{O}_{22}\right)$, and the sourcing quantity is 200, 269.92 respectively. Other variables remain the same. In addition, it shows that the lower raw material costs of the market help independent suppliers to get more order quantity. The formation of the optimal ACSCC of this case 
belongs to the second combination form of CSC, as shown in Fig. 2(b).

\section{Conclusions}

In this paper, we studied various combination forms of the three basic sharing elements (i.e. orders sharing, manufacturers capacity sharing and suppliers capacity sharing) in the CSC and analysed the operational mechanism of each combination form. Through analysis and division of self-decision rights of participants in the industrial cluster, a distributed ACSCC model has been set up considering simultaneously multiple sharing elements, particularly, allowing cross-chain to source from private suppliers of other single supply chains, which differs from the existing literature (Qu et.al 2015, 2017). ALC was applied to solve the ACSCC model. Especially, an improved ALC was put forward considering the trade-off between parallelism, efficiency and accuracy. The improved ALC was applied to a mathematical programming problem and the ACSCC problem. From the perspective of efficiency, experimental results successfully demonstrated the practical effectiveness of this method.

The main contributions of this research include the following. Firstly, the operational mechanism of each combination form composed of three base sharing elements (i.e. orders sharing, manufacturers capacity sharing and suppliers capacity sharing) was systematic analysed. A distributed ACSCC model was established considering simultaneously orders sharing, manufacturer's capacity sharing, private supplier's capacity sharing and independent supplier's sharing. Secondly, the ALC with open architectures was applied to solve the ACSCC problem considering simultaneously multiple sharing elements and multiple constraints. Especially, an improved ALC method, which uses the existing the sub-problem to coordinate other sub-problems, was put forward because that the centralized ALC method consumes more computational resources using the artificial main problem. Finally, a set of sensitivity analysis was conducted and some important managerial implications for cluster participants were obtained.

The future works of this research are as follows: First, this paper formulated the single-period ACSCC model and investigated the operation mechanism of each combination form composed of three base sharing elements. However, a multi-period ACSCC model is to be developed and a more comprehensive investigation of the relationships among combination forms is to be extended in the future. Second, the theoretical convergence proof of the improved ALC was not given here, yet, when the improved ALC is to be used to resolve the optimal design problems of other more complex industrial systems such as aircrafts, a rigid proof is necessary and deserves our further studying. 


\section{Acknowledgements}

This work was supported by the Guangdong Natural Science Foundation (2017A030313401), China Scholarship Council (201807630004), the National Natural Science Foundation of China (51475095, 61473093) and Key Project of Guangdong Natural Science Foundation (2016A030311041).

\section{APPENDIX}

Table 5 Results comparison between Improved ALC, Centralized ALC and Lingo11

\begin{tabular}{|c|c|c|c|}
\hline \multirow{3}{*}{$\begin{array}{l}\text { Optimal } \\
\text { objective }\end{array}$} & \multicolumn{3}{|c|}{ Method } \\
\hline & Lingo11 & Improved ALC & Centralized ALC \\
\hline & Optimal values & Optimal values & Optimal values \\
\hline$d_{i}$ & {$[0.720,0,0,0,0.28]$} & {$[0.720,0,0,0,0.28]$} & {$[0.720,0,0,0,0.28]$} \\
\hline \multirow[t]{3}{*}{$\eta_{i}$} & {$[1,0,0,0,1]$} & {$\left[\begin{array}{lllll}1, & 0, & 0, & 0, & 1\end{array}\right]$} & {$[1,0,0,0,1]$} \\
\hline & {$[0,0,0$} & {$[0,0,0$} & {$[0,0,0$} \\
\hline & $0,0,0$ & $0,0,0$ & $0,0,0$ \\
\hline \multirow{5}{*}{$y_{i 1 t}$} & $0,0,0$ & $0,0,0$ & $0,0,0$ \\
\hline & $0,0,0$ & $0,0,0$ & $0,0,0$ \\
\hline & $0,0,0]$ & $0,0,0]$ & $0,0,0]$ \\
\hline & {$[0,270,0$} & {$[0,269.89,0$} & {$[0,269.96,0$} \\
\hline & $0,0,0$ & $0,0,0$ & $0,0,0$ \\
\hline \multirow{5}{*}{$y_{i 2 t}$} & $0,0,0$ & $0,0,0$ & $0,0,0$ \\
\hline & $0,0,0$ & $0,0,0$ & $0,0,0$ \\
\hline & $0,0,0]$ & $0,0,0]$ & $0,0,0]$ \\
\hline & {$[1,1$} & {$[1,1$} & {$[1,1$} \\
\hline & 0,0 & 0,0 & 0,0 \\
\hline$w_{i j}$ & 0,0 & 0,0 & 0,0 \\
\hline & 0,0 & 0,0 & 0,0 \\
\hline & $0,0]$ & $0,0]$ & $0,0]$ \\
\hline & {$[0.72222,0.625$} & {$[0.72222,0.625$} & {$[0.72222,0.625$} \\
\hline & 0 , & 0 & 0 \\
\hline$d_{i j}$ & 0 , & 0 & $0, \quad 0$ \\
\hline & 0 & 0 & $0, \quad 0$ \\
\hline & $1, \quad 1]$ & $1, \quad 1]$ & $1, \quad 1]$ \\
\hline & {$[0,0,150,50$} & {$[0,0,149.60,50.40$} & {$[0,0,149.92,50.08$} \\
\hline & $0,0,0,0$ & $0,0,0,0$ & $0,0,0,0$ \\
\hline$z_{i r 1}$ & $0,0,0,0$ & $0,0,0,0$ & $0,0,0,0$ \\
\hline & $0,0,0,0$ & $0,0,0,0$ & $0,0,0,0$ \\
\hline & $0,0,0,0]$ & $0,0,0,0]$ & $0,0,0,0]$ \\
\hline & {$[0,0,0,0$} & {$[0,0,0,0$} & {$[0,0,0,0$} \\
\hline$z_{j i r}$ & $0,0,0,0$ & $0,0,0,0$ & $0,0,0,0$ \\
\hline vir 2 & $0,0,0,0$ & $0,0,0,0$ & $0,0,0,0$ \\
\hline & $0,0,0,0$ & $0,0,0,0$ & $0,0,0,0$ \\
\hline
\end{tabular}




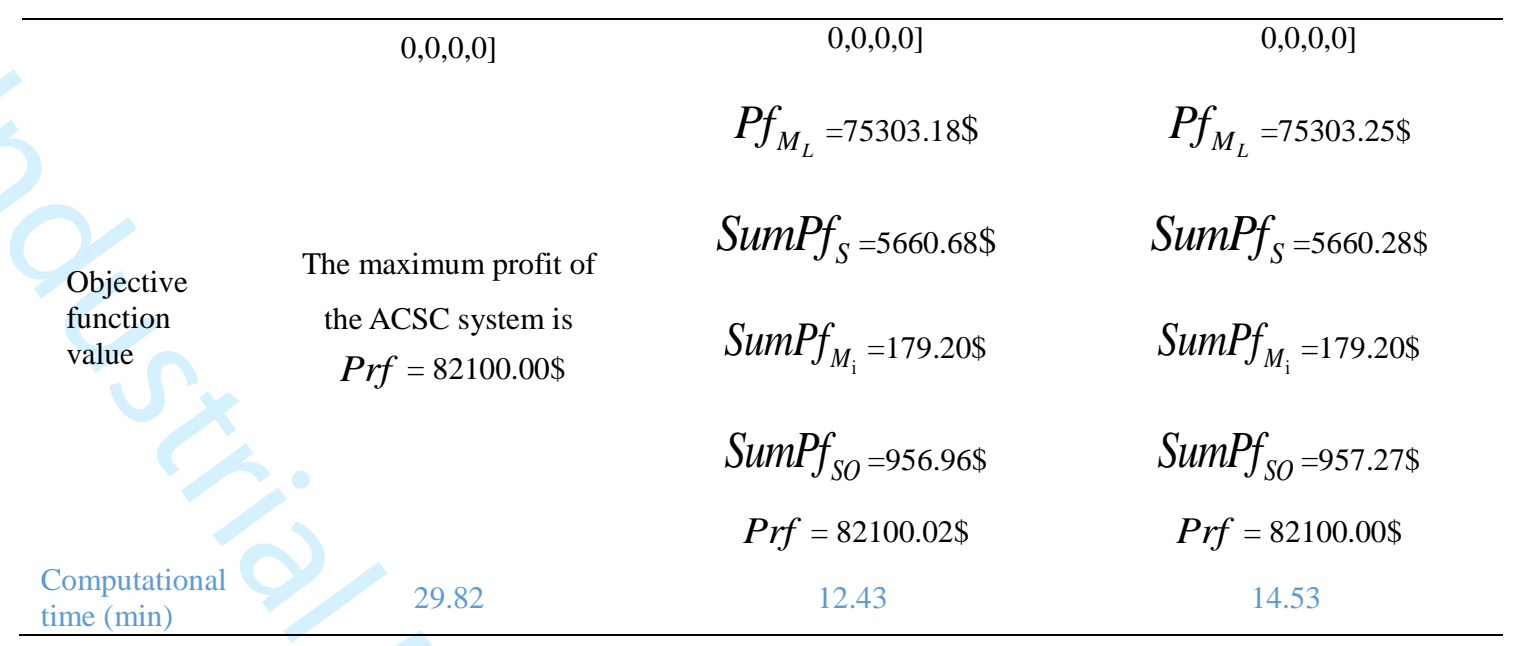

Table 6 Optimal results compared with the previous under the rise of sales price

\begin{tabular}{|c|c|c|}
\hline $\begin{array}{c}\text { Objective } \\
\text { Parameter }\end{array}$ & Optimal values & The previous Optimal values \\
\hline$P f_{M_{L}}$ & $73704.52 \$$ & $75303.18 \$$ \\
\hline $\operatorname{SumPf}_{S}$ & $7946.281 \$$ & $5660.68 \$$ \\
\hline $\operatorname{SumPf}_{M_{\mathrm{i}}}$ & $179.20 \$$ & $179.20 \$$ \\
\hline $\operatorname{SumPf}_{S O}$ & 0 & $956.96 \$$ \\
\hline$d_{i}$ & {$[0.720,0,0,0,0.28]$} & {$[0.720,0,0,0,0.28]$} \\
\hline$\eta_{i}$ & {$[1,0,0,0,1]$} & {$[1,0,0,0,1]$} \\
\hline$y_{i 1 t}$ & $\begin{array}{c}{[0,0,0} \\
0,0,0 \\
0,0,0 \\
0,0,0 \\
0,0,0]\end{array}$ & $\begin{array}{c}{[0,0,0} \\
0,0,0 \\
0,0,0 \\
0,0,0 \\
0,0,0]\end{array}$ \\
\hline$y_{i 2 t}$ & $\begin{array}{c}{[0,0,0} \\
0,0,0 \\
0,0,0 \\
0,0,0 \\
0,0,0]\end{array}$ & $\begin{array}{c}{[0,269.89,0} \\
0,0,0 \\
0,0,0 \\
0,0,0 \\
0,0,0]\end{array}$ \\
\hline & {$[1,1$} & {$[1,1$} \\
\hline & 0,0 & 0,0 \\
\hline$w_{i j}$ & 0,0 & 0,0 \\
\hline & 0,0 & 0,0 \\
\hline \multirow[b]{2}{*}{$d_{i j}$} & $0,0]$ & $0,0]$ \\
\hline & $\begin{array}{cc}{[0.72222,} & 0.625 \\
0, & 0 \\
0, & 0 \\
0, & 0 \\
1, & 1]\end{array}$ & $\begin{array}{cc}{[0.72222,} & 0.625 \\
0, & 0 \\
0, & 0 \\
0, & 0 \\
1, & 1]\end{array}$ \\
\hline$z_{i r 1}$ & $\begin{array}{c}{[0,0,149.60,50.40} \\
0,0,0,0 \\
0,0,0,0 \\
0,0,0,0 \\
0,0,0,0]\end{array}$ & $\begin{array}{c}{[0,0,149.60,50.40} \\
0,0,0,0 \\
0,0,0,0 \\
0,0,0,0 \\
0,0,0,0]\end{array}$ \\
\hline$z_{i r 2}$ & {$[0,270,0,0$} & {$[0,0,0,0$} \\
\hline
\end{tabular}




\begin{tabular}{cc}
\hline $0,0,0,0$ & $0,0,0,0$ \\
$0,0,0,0$ & $0,0,0,0$ \\
$0,0,0,0$ & $0,0,0,0$ \\
$0,0,0,0]$ & $0,0,0,0]$ \\
\hline
\end{tabular}

Table 7 Optimal results compared with the previous under lower sales price

\begin{tabular}{|c|c|c|}
\hline $\begin{array}{c}\text { Objective } \\
\text { Parameter }\end{array}$ & Optimal values & The previous Optimal values \\
\hline$P f_{M_{L}}$ & $76669.95 \$$ & $75303.18 \$$ \\
\hline $\operatorname{SumPf}_{S}$ & $4140 \$$ & $5660.68 \$$ \\
\hline $\operatorname{SumPf}_{M_{\mathrm{i}}}$ & $179.20 \$$ & $179.20 \$$ \\
\hline SumPf $_{\text {SO }}$ & $1580.846 \$$ & $956.96 \$$ \\
\hline$d_{i}$ & {$[0.720,0,0,0,0.28]$} & {$[0.720,0,0,0,0.28]$} \\
\hline$\eta_{i}$ & {$[1,1,0,0,0,1]$} & {$\left[\begin{array}{lllll}1, & 0, & 0, & 0, & 1\end{array}\right]$} \\
\hline & {$[0,200,0$} & $\begin{array}{c}{[0,0,0} \\
0,0,0\end{array}$ \\
\hline$y_{i 1 t}$ & $0,0,0$ & $0,0,0$ \\
\hline & \multirow{2}{*}{$\begin{array}{l}0,0,0 \\
0,0,0]\end{array}$} & $0,0,0$ \\
\hline & & $0,0,0]$ \\
\hline & {$[0,269.92,0$} & {$[0,269.89,0$} \\
\hline & \multirow{2}{*}{$\begin{array}{l}0,0,0 \\
0,0,0\end{array}$} & $0,0,0$ \\
\hline$y_{i 2 t}$ & & $0,0,0$ \\
\hline & $0,0,0$ & $0,0,0$ \\
\hline & $0,0,0]$ & $0,0,0]$ \\
\hline$w_{i j}$ & $\begin{array}{c}{[1,1} \\
0,0 \\
0,0 \\
0,0 \\
0,0]\end{array}$ & $\begin{array}{c}{[1,1} \\
0,0 \\
0,0 \\
0,0 \\
0,0]\end{array}$ \\
\hline$d_{i j}$ & $\begin{array}{cc}{[0.72222,} & 0.625 \\
0, & 0 \\
0, & 0 \\
0, & 0 \\
1, & 1]\end{array}$ & $\begin{array}{cc}{[0.72222,} & 0.625 \\
0, & 0 \\
0, & 0 \\
0, & 0 \\
1, & 1]\end{array}$ \\
\hline$z_{i r 1}$ & $\begin{array}{c}{[0,0,0,0} \\
0,0,0,0 \\
0,0,0,0 \\
0,0,0,0 \\
0,0,0,0]\end{array}$ & $\begin{array}{c}{[0,0,149.60,50.40} \\
0,0,0,0 \\
0,0,0,0 \\
0,0,0,0 \\
0,0,0,0]\end{array}$ \\
\hline$z_{i r 2}$ & $\begin{array}{l}{[0,0,0,0} \\
0,0,0,0 \\
0,0,0,0 \\
0,0,0,0 \\
0,0,0,0]\end{array}$ & $\begin{array}{c}{[0,0,0,0} \\
0,0,0,0 \\
0,0,0,0 \\
0,0,0,0 \\
0,0,0,0]\end{array}$ \\
\hline
\end{tabular}




\section{References}

Afrouzy, Z. A., Nasseri, S. H., \& Mahdavi, I. (2016). “A genetic algorithm for supply chain configuration with new product development". Computers \& Industrial Engineering. Vol.101, pp.440-454.

Allison, J., Papalambros, P.Y. (2010). “Consistency Constraint Allocation in Augmented Lagrangian Coordination”. Journal of Mechanical Design, Vol.132 No. 7, pp.1-8.

Amini, M., \& Li, H. (2015). "The impact of dual-market on supply chain configuration for new products”. International Journal of Production Research, Vol.53 No.18,pp. 5669-5684.

Bikram, K., Bahinipati, A.K., Deshmukh, S.G. (2009). "Horizontal collaboration in semiconductor manufacturing industry supply chain An evaluation of collaboration intensity index". Computers and Industrial Engineering, Vol.57,pp. 880-895.

Camarinha-Matos, L.M., Afsarmanesh, H., Galeano, N. et al. (2009). "Collaborative networked organizations - Concepts and practice in manufacturing enterprises". Computers and Industrial Engineering, Vol.1 No.57, pp.46-60.

DeWitt, T., Giunipero, L. C., \& Melton, H. L. (2006). “ Clusters and supply chain management: the Amish experience". International Journal of Physical Distribution and Logistics Mangement, Vol.36 No.4, pp.289-308..

Graves S C, Willems S P. (2001). "Optimizing the supply chain configuration for new products". Working paper. Leaders for Management Program and A.P., Sloan School of Management, MIT.

Huang, G.Q., Qu, T. (2008). "Extending Analytical Target Cascading for Optimal Configuration of Supply Chains with Alternative Autonomous Suppliers". International Journal of Production Economics, Vol.115, pp.39-54.

Huang G Q, Zhang X Y, Liang L. (2005). "Towards integrated optimal configuration of platform products, manufacturing processes, and supply chains". Journal of Production Economics, Vol.23 No.(2-4),pp.267-290.

Kannan, D., Khodaverdi, R., Olfat, L., Jafarian, A., \& Diabat, A. (2013). "Integrated fuzzy multi criteria decision making method and multi-objective programming approach for supplier selection and order allocation in a green supply chain”. Journal of Cleaner Production, Vol.47, pp. 355-367.

Kawtummachai, R., \& Van Hop, N. (2005). "Order allocation in a multiple-supplier environment". International Journal of Production Economics, Vol.93,pp. 231-238.

Kim, H. M., Michelena, N. F., Papalambros, P. Y., \& Jiang, T. (2003). "Target cascading in optimal system design”. Journal of mechanical design, Vol.125 No.3, pp.474-480.

Klosterhalfen, S. T., Minner, S., \& Willems, S. P. (2014). "Strategic safety stock placement in supply networks with static dual supply". Manufacturing \& Service Operations Management, Vol.16 No.2, pp.204-219.

Li, J.Z, Xiong, N.X., Park, J.H., et al. (2012). "Intelligent model design of cluster supply chain with horizontal cooperation”. Journal of Intelligent Manufacturing, Vol.23, pp.917-931.

Luo, Y. (2007). “A coopetition perspective of global competition”. Journal of world business, Vol 42 No.2,pp. 129-144. 
Meysam, S. K., Maghsud, S., \& Ali, D. (2016). “An integrated supply chain configuration model and procurement management under uncertainty: A set-based robust optimization methodology". Applied Mathematical Modelling. Vol.40 No.17-18, pp.7928-7947.

Porter, M.E. (2000), Location, "Competition, and Economic Development: Local Clusters in A Global Economy", Economic Development Quarterly Vol.14 No.1, pp.15- 20.

Qu, T. Huang, G.Q., Cung, Van-Dat, Mangione, Fabien. (2010). “Optimal Configuration of Assembly Supply Chains Using Analytical Target Cascading”. International Journal of Production Research, Vol48 No.23,pp. 6883- 6907.

Qu, T., Nie, D. X., Chen, X., et al. (2015). “Optimal configuration of cluster supply chains with augmented Lagrange coordination”. Computers \& Industrial Engineering, Vol.84,pp. 43-55.

Qu, T., Nie, D. X., Li. C.D. et al. (2017). “Optimal configuration of assembly supply chains based on Hybrid augmented Lagrangian coordination in an industrial cluster". Computers \& Industrial Engineering, Vol.112,pp.511-525.

Renna, P., \& Perrone, G. (2015). “Order allocation in a multiple suppliers-manufacturers environment within a dynamic cluster". The International Journal of Advanced Manufacturing Technology, Vol.80 No.1-4, pp.171-182.

Rezaei, J., Nispeling, T., Sarkis, J., \& Tavasszy, L. (2016). “A supplier selection life cycle approach integrating traditional and environmental criteria using the best worst method". Journal of Cleaner Production, Vol.135,pp. 577-588.

Roelandt, T. J., \& Den Hertog, P. (1999). "Cluster Analysis and Cluster-based Policy Making: The State of the Art", In Cluster Analysis and Cluster-based Policy: New Perspectives and Rationale in Innovation Policy. Ed. T Roelandt and P. den Hertog. Paris: Organisation for Economic Cooperation and Development.

Tosserams ,S., Etman LFP, Rooda JE. (2007). “An augmented Lagrangian decomposition method for quasi-separable problems in MDO. Structural and Multidisciplinary Optimization", Vol.34 No.3, pp.211-227.

Tosserams, S., Etman, L.F.P., and Rooda, J.E. (2008). “Augmented Lagrangian coordination for distributed optimal design in MDO”. International Journal for Numerical Methods in Engineering, Vol.73 No.13, pp. 1885-1910.

Tosserams S., L. F. P. Etman, and J. E. Rooda. (2010a). “A micro-accelerometer MDO benchmark problem". Structural and Multidisciplinary Optimization, Vol.41 No.2,pp. 255-275.

Tosserams S, M. Kokkolaras, L. F. P. Etman, and J. E. Rooda. (2010b), “A Nonhierarchical formulation of analytical target cascading”. Journal of Mechanical Design, Vol.132 No.5, pp.051002. Xiang, W., Song, F., \& Ye, F. (2014). “Order allocation for multiple supply-demand networks within a cluster”. Journal of Intelligent Manufacturing, Vol.25 No.6,pp. 1367-1376.

Xu M, G. Fadel, and M. M. Wiecek. (2015). "Dual residual for centralized augmented Lagrangian coordination based on optimality conditions". Journal of Mechanical Design, Vol.137No.6, pp. 061401 . 